\title{
Dysfunction of Cellular Proteostasis in Parkinson's Disease
}

\author{
Šárka Lehtonen ${ }^{1,2}$, Tuuli-Maria Sonninen ${ }^{1}$, Sara Wojciechowski', Gundars Goldsteins ${ }^{1}$ \\ and Jari Koistinaho ${ }^{1,2 *}$
}

'A.I. Virtanen Institute for Molecular Sciences, University of Eastern Finland, Kuopio, Finland, ${ }^{2}$ Neuroscience Center, Helsinki Institute of Life Science, University of Helsinki, Helsinki, Finland

Despite decades of research, current therapeutic interventions for Parkinson's disease (PD) are insufficient as they fail to modify disease progression by ameliorating the underlying pathology. Cellular proteostasis (protein homeostasis) is an essential factor in maintaining a persistent environment for neuronal activity. Proteostasis is ensured by mechanisms including regulation of protein translation, chaperone-assisted protein folding and protein degradation pathways. It is generally accepted that deficits in proteostasis are linked to various neurodegenerative diseases including PD. While the proteasome fails to degrade large protein aggregates, particularly alpha-synuclein $(\alpha-S Y N)$ in PD, drug-induced activation of autophagy can efficiently remove aggregates and prevent degeneration of dopaminergic (DA) neurons. Therefore, maintenance of these mechanisms is essential to preserve all cellular functions relying on a correctly folded proteome. The correlations between endoplasmic reticulum (ER) stress and the unfolded protein response (UPR) that aims to restore proteostasis within the secretory pathway are well-established. However, while mild insults increase the activity of chaperones, prolonged cell stress, or insufficient adaptive response causes cell death. Modulating the activity of molecular chaperones, such as protein disulfide isomerase which assists refolding and contributes to the removal of unfolded proteins, and their associated pathways may offer a new approach for disease-modifying treatment. Here, we summarize some of the key concepts and emerging ideas on the relation of protein aggregation and imbalanced proteostasis with an emphasis on PD as our area of main expertise. Furthermore, we discuss recent insights into the strategies for reducing the toxic effects of protein unfolding in PD by targeting the ER UPR pathway.

Keywords: proteostasis, alpha-synuclein, refolding, ER stress, UPR, protein disulfide isomerase

\section{INTRODUCTION}

In Parkinson's disease (PD), the loss of dopaminergic (DA) neurons in the substantia nigra pars compacta $(\mathrm{SNpc}$ ) and subsequent loss of dopamine in the striatum leads to typical motor impairments in $\mathrm{PD}$, such as bradykinesia, rigidity, rest tremor, and postural instability. There are various non-motor symptoms also associated with PD including anosmia, gastrointestinal motility issues, sleep disturbances, sympathetic denervation, anxiety, and depression. These non-motor symptoms generally precede the motor impairments by years (Kalia and Lang, 2015). The presence of Lewy bodies (LBs) with an accumulation of the protein alpha-synuclein ( $\alpha$-SYN) is one of the 
pathological hallmarks in PD (Kalia and Lang, 2015; Sveinbjornsdottir, 2016). There is not yet a cure, although, treatments are available to relieve symptoms. Approximately 20 $\mathrm{PD}$-associated genes have been identified to date even though most cases are late onset and sporadic with no evidence for inheritance or genetic cause (Klein and Westenberger, 2012). The phenotypes of both the sporadic and familial forms are essentially indistinguishable, implying that they might share common underlying mechanisms. Moreover, many similarities including protein misfolding and aggregation are also commonly seen in other neurodegenerative diseases. While the exact role of protein aggregation in disease pathology is still under debate, discovering these similarities offers hope for therapeutic advances that could affect many diseases simultaneously. In this review, we summarize recent progress in the studies on the mechanism of endoplasmic reticulum (ER) stressinduced unfolded protein response (UPR) in PD, how protein aggregation relates to imbalanced proteostasis and how to remedy the toxic effects of protein unfolding in $\mathrm{PD}$ by targeting the ER UPR pathway.

\section{DESCRIPTION OF CELLULAR PROTEOSTASIS DEFICITS IN PD}

\section{Physiological Role of $\alpha-S Y N$ and Aggregation}

$\alpha-S Y N$ is a small $(14 \mathrm{kDa})$ protein that is highly expressed in neurons but can also be found in peripheral tissues and blood (Witt, 2013; Malek et al., 2014). A recent report also demonstrated its expression in astrocytes (di Domenico et al., 2019). The physiological function of $\alpha$-SYN remains mostly undefined (Devine et al., 2011; Liu et al., 2012; Kalia and Kalia, 2015), nevertheless, the involvement in synaptic maintenance, mitochondrial homeostasis, dopamine metabolism, and chaperone activity has been studied. Typically, $\alpha-S Y N$ is a monomer with three structural regions (Villar-Piqué et al., 2016). The N-terminal domain (1-60) contains a multirepeated consensus sequence (KTKEGV) and is responsible for the membrane-binding capacity. The central domain (61-95) is known as the non-amyloid-beta component and contains a highly hydrophobic motif which is involved in $\alpha-S Y N$ aggregation. The C-terminal domain's (96-140) proline residues have been found to be acidic. The exact native structure of $\alpha$-SYN is not completely established, but several studies have described it as a soluble protein with a disordered monomeric structure (Binolfi et al., 2012; Fauvet et al., 2012; Waudby et al., 2013). In addition, soluble tetramers have been identified (Bartels et al., 2011), but the physiologically relevant structure of $\alpha$-SYN may differ depending on the cellular location and environment. The non-amyloid-beta domain of $\alpha$-SYN is prone to aggregate, but in its native structure, it appears to be protected by the $\mathrm{N}$ - and C-termini (Bertoncini et al., 2005). Changes in environment, mutations and/or post-translational modifications (PTMs) may disrupt the native conformation of $\alpha-\mathrm{SYN}$ and induce misfolding and aggregation.
Initially, $\alpha-S Y N$ was identified in the nucleus, but this is still in dispute (Huang et al., 2011). It has been proposed that the nuclear protein TRIM28 regulates its translocation into the nucleus and $\alpha$-SYN may play a role in transcription regulation and histone acetylation (Kontopoulos et al., 2006; Rousseaux et al., 2016). Several studies have shown that PD associated mutations, PTMs and oxidative stress can increase the nuclear localization of $\alpha$-SYN (Kontopoulos et al., 2006; Xu et al., 2006; Schell et al., 2009; Gonçalves and Outeiro, 2013; Fares et al., 2014). In addition, animal and cellular models and patient studies have shown altered activation of transcription factors upon $\alpha-S Y N$ translocation. These include decreased activation of the mitochondrial biogenesis factor PGC- $1 \alpha$, reduced activation of the autophagy-lysosomal pathway (ALP) transcription factor EB (TFEB), and increased activation of calcineurin and subsequent nuclear translocation of nuclear factor of activated $\mathrm{T}$ cells (Decressac et al., 2013; Ryan et al., 2013; Luo et al., 2014; Eschbach et al., 2015).

$\alpha$-SYN is associated with several neurodegenerative disorders, collectively known as synucleinopathies (Wong and Krainc, 2017). $\alpha$-SYN fibrils are the main component found in LB and Lewy neurites (LNs) in PD and dementia with Lewy bodies (DLBs). LBs are spherical aggregates of $\alpha$-SYN found in neuronal cell bodies, while LNs are aggregate structures found in neuronal dendrites and axons. Structurally, LBs are made up of insoluble eosinophilic amyloid that is surrounded by fibrils of $\alpha$-SYN which are typically ubiquitinated (Beyer et al., 2009). In sporadic PD, $\alpha$-SYN accumulates in neuronal cell bodies and processes resulting in LBs and LNs, respectively. Duplication of SNCA results in late-onset autosomal dominant forms of $\mathrm{PD}$ and triplication results in early-onset PD (Singleton et al., 2003). This demonstrates that $\alpha$-SYN levels correlate with the onset of PD. In addition, other mutations causing familial PD, like mutations in leucine-rich repeat kinase 2 (LRRK2), can develop LB pathology (Zimprich et al., 2004). When comparing the pathology of DLB, there are some similarities with PD, but the clinical symptoms are closer to Alzheimer's disease (Spillantini et al., 1998). In PD, the substantia nigra (SN) is affected, while in DLB the pathology is seen in the cortex. In addition to PD and DLB, $\alpha-S Y N$ accumulation is present in multiple system atrophy (MSA) and pure autonomic failure (PAF). In MSA the $\alpha$-SYN inclusions are present in the cytosol of oligodendrocytes. Mutations in $\alpha-S Y N$ can cause both PD and MSA symptoms (Fanciulli and Wenning, 2015). LBs and LNs are found in the sympathetic nervous system in PAF (Arai et al., 2000). In addition to synucleinopathies, $\alpha$-SYN toxicity has been associated with lysosomal storage disorders such as Gaucher's disease, a rare genetic disorder characterized by the deposition of glucocerebroside in cells of the macrophage-monocyte system (Blanz and Saftig, 2016). Mutations in GBA1, which encodes glucocerebrosidase (GCase) and causes Gaucher's disease, are the most common risk factors for PD. Some patients carrying these mutations may develop parkinsonism, a clinical syndrome characterized by movement disorders commonly seen in PD, with LB pathology.

Oligomers and fibrils are considered to be the toxic species of $\alpha$-SYN, but there remains some disagreement regarding their 
toxicity. Several studies have suggested that soluble oligomers are more toxic than fibrils or aggregates. For example, increased levels of soluble oligomers have been identified in $\alpha-S Y N$ transgenic mice and in PD and DLB patient brains. Oligomeric $\alpha-S Y N$ caused more severe DA neuron loss than fibrils in rats (Sharon et al., 2003; Winner et al., 2011). By contrast, some studies have shown fibrils to be more toxic compared to the oligomers and caused increased motor impairment, DA cell loss and synaptic impairment (Peelaerts et al., 2015).

In neurons, $\alpha-S Y N$ is known to localize in presynaptic terminals and regulate synaptic transmission. The release of neurotransmitters requires cycles of soluble $N$-ethylmaleimidesensitive factor attachment protein receptor (SNARE)-complex assembly and disassembly. $\alpha$-SYN has been shown to bind to SNARE protein synaptobrevin-2/vesicle-associated membrane protein 2 (VAMP2) and promote SNARE-complex assembly (Burré et al., 2010). The same study also demonstrated that triple knockout mice developed neurological impairments and had decreased SNARE assembly. Subsequently, it was described that $\alpha$-SYN promotes vesicle-clustering activity, which is dependent on the interaction of $\alpha$-SYN with synaptobrevin-2/VAMP2 and anionic lipids (Diao et al., 2013). These studies suggest that the major cellular function of $\alpha-S Y N$ are interactions of $\alpha$-SYN with cell membranes, and that the cytosolic state may be transient.

While $\alpha$-SYN is normally localized in presynaptic terminals, the oligomers and aggregates can be found in cell bodies and neurites, as well as in other cell types, including astrocytes which indicates a widespread toxic action. The pathological effects of $\alpha$-SYN can affect the function of several different organelles, including synaptic vesicles, mitochondria, lipid bilayers, cell's cytoskeleton, ER, Golgi, proteasomes, lysosomes, and nucleus. $\alpha$-SYN oligomers can disrupt the SNARE complex formation, dopamine release and synaptic-vesicle motility (Choi et al., 2013; Wang et al., 2014). Increased levels of $\alpha-S Y N$ can also decrease the synaptic-vesicle recycling-pool size and mobility leading to a disrupted neurotransmitter release (Nemani et al., 2010; Scott and Roy, 2012). It was discovered that dopamine neurotransmission can be disrupted by high levels of $\alpha$-SYN. Transgenic mice overexpressing $\alpha-S Y N$ showed a DA terminal loss, deficient release and altered synaptic-vesicle distribution (Masliah et al., 2000; Janezic et al., 2013). Moreover, the reduction in dopamine reuptake and defective dopamine transporter function has been linked to increased levels of $\alpha-S Y N$ (Lundblad et al., 2012).

The homeostasis of mitochondria can be disrupted by $\alpha-S Y N$ toxicity. Mice with an A53T $\alpha-S Y N$ mutation have increased mitochondrial DNA damage and upregulated mitophagy (Martin et al., 2006; Choubey et al., 2011; Chen et al., 2015). In contrast, a recent study showed delayed mitophagy in PD patient neurons caused by abnormal accumulation of Miro protein (Shaltouki et al., 2018). $\alpha$-SYN oligomers also reduced axonal mitochondria transport in induced pluripotent stem cell (iPSC)- derived neurons (Prots et al., 2018). Recent studies have also shown that $\alpha$-SYN translocated to the mitochondrial matrix and caused impairment of complex I leading to decreased ATP synthesis and increased reactive oxygen species (ROS) production
(Martínez et al., 2018). These results suggest that $\alpha$-SYN can disrupt the mitochondrial homeostasis in several ways.

$\alpha$-SYN oligomers can interact with and permeabilize lipid membranes causing structural alterations of the intracellular and plasma membranes, increase of intracellular calcium levels, and activation of calpain (van Rooijen et al., 2010; Melachroinou et al., 2013; Ronzitti et al., 2014). Additionally, $\alpha$-SYN oligomers can inhibit tubulin polymerization and impair neurite network morphology and overexpression in cultured cells and cause microtubule destabilization and neurite degeneration (Lee et al., 2006; Chen et al., 2007; Prots et al., 2013). $\alpha$-SYN fibrils have also been shown to impair axonal transport of autophagosomes and endosomes but the fibrils didn't affect the transport of synaptophysin or mitochondria (Volpicelli-Daley et al., 2014). However, a recent study found that $\alpha$-SYN oligomers disrupted anterograde axonal transport of mitochondria and caused subcellular changes in transport-regulating proteins in iPSCderived neurons (Prots et al., 2018).

\section{Major Pathways of Alpha-Synuclein Clearence in PD}

The protein degradation system is part of a protein quality control machinery which clears non-essential misfolded, or damaged proteins. The two major protein degradation systems are the ubiquitin-proteasome pathway (UPP) and ALP. Both are affected in synucleinopathies. These pathways have been shown to be responsible for degrading $\alpha-S Y N$, and failure in one or both can lead to accumulation. The progressive accumulation of $\alpha$-SYN typical in PD can be linked to the disruption of the UPP by aggregation (Lindersson et al., 2004) as well as different types of autophagy (Winslow et al., 2010; Malkus and Ischiropoulos, 2012). It has been shown that aggregated $\alpha-S Y N$ can bind to the membrane proteins of lysosomes and block their function (Malkus and Ischiropoulos, 2012) as well as inhibit certain enzymatic activity domains of proteasomes (Lindersson et al., 2004). $\alpha$-SYN also inhibits the expression of proteins relevant to autophagosome assembly leading to inefficient removal of aggregated proteins due to impairment in macroautophagy (Winslow et al., 2010).

\section{The Ubiquitin-Proteasome Pathway}

In the UPP, short-living proteins that are coupled with ubiquitin molecules are degraded by proteasomes (Pickart, 2001; Glickman and Ciechanover, 2002) (Figure 1A). The first evidence of UPP failure in PD came from post-mortem studies that used enzymatic assays to evaluate proteasome activity in brain tissues. These studies showed a significant decrease in the chymotrypsinlike and trypsin-like proteasome activity in the SN of PD patients in comparison to age-matched controls. No evidence of defective proteasome activity was seen in other brain regions but rather increased activity was observed in the unaffected areas (Furukawa et al., 2002). These studies suggested that reduced proteasome activity is specific for certain brain regions, like SN. In contrast, it is probable that the decreased activity of proteasomes could be a consequence of the neurodegeneration in this region.

Reduced levels of proteasome subunits have been observed in $\mathrm{PD}$ patients. Several genes that code for proteasome subunits 


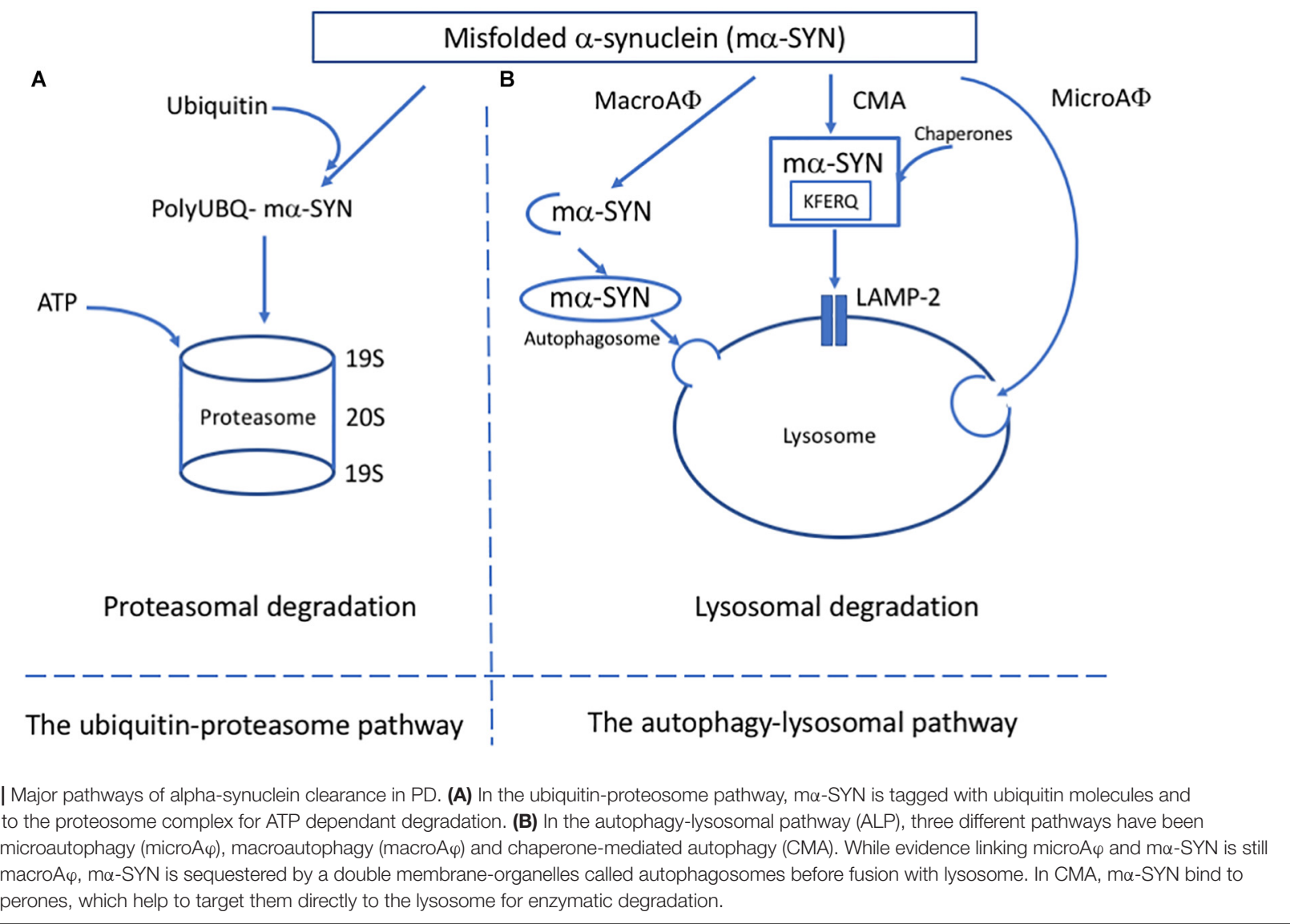

were downregulated in the $\mathrm{SN}$ of $\mathrm{PD}$ patients and were linked to reduced levels of $20 \mathrm{~S}$ proteasome core, $\alpha$-subunit and 19S regulatory caps (Furukawa et al., 2002; McNaught et al., 2002a, 2003; Grünblatt et al., 2004; Chu et al., 2009; Bukhatwa et al., 2010).

Some studies have demonstrated altered proteasome function in peripheral blood cells of PD patients, but the results were significant only in patients treated with L-DOPA and dopamine agonists (Blandini et al., 2006; Ullrich et al., 2010). This indicates that dopamine levels can alter the proteasome function and is supported by animal and in vitro models (Yoshimoto et al., 2005; Berthet et al., 2012).

Studies with disease models have implicated the dysfunction of UPP in PD. Treatment with proteasome inhibitor lactacystin leads to dose-dependent neurodegeneration and formation of ubiquitin and $\alpha$-SYN positive inclusions in $\alpha$-SYN-eGFP transfected mouse primary neurons, rat ventral mesencephalic primary neurons, and cultured PC12 cells (McLean et al., 2001; Rideout et al., 2001; McNaught et al., 2002b). McNaught and colleagues used a systemic application of proteasome inhibitor in rats which led to motor deficits and main pathological features typical for PD (McNaught et al., 2004). Also, neurons were found to contain $\alpha-S Y N$ and ubiquitin-positive inclusion bodies. Since then, this model has been challenged due to several laboratories inability to replicate the model (more information, see review, Bentea et al., 2017). Besides these studies, toxinbased animal and cellular models have implicated a link between sporadic PD and UPP failure. The toxin 1-methyl-4-phenyl1,2,3,6-tetrahydropyridine (MPTP) appears to target specifically those neurons that are involved in PD. MPTP can easily cross the blood-brain barrier and then is metabolized by astrocytes to become 1-methyl-4-phenylpyridinium $(\mathrm{MPP}++)$ ion which is also toxic. $\mathrm{MPP}+$ is released from astrocytes and taken up by DA neurons. MPTP administration causes nigral cell loss, striatal dopamine loss and behavioral deficits (Meredith and Rademacher, 2011). Several in vitro experiments have shown decreased proteasome activity after exposure of pesticides and environmental toxins linked to PD (Wang et al., 2006; Caneda-Ferrón et al., 2008; Chou et al., 2010). Consistent with these findings, in vivo studies showed reduced proteasome activity after rotenone and MPTP administration (Fornai et al., 2005; Betarbet et al., 2006). The UPP impairment caused by MPTP was alleviated in mice lacking $\alpha$-SYN suggesting that it increases the detrimental effects of MPTP on the UPP (Fornai et al., 2005).

Numerous in vitro studies with purified proteins or cell culture systems, have demonstrated that mutant or wildtype $\alpha$-SYN can inhibit $20 \mathrm{~S}$ or $26 \mathrm{~S}$ proteasome activity, especially in the case of oligomer or fibril formation. In PC12 cells expressing human mutant A53T $\alpha$-SYN, cells 
exhibited accumulation of cytoplasmic ubiquitinated aggregates corresponding with decreased proteasomal chymotrypsin-like activity measured from cell lysates (Stefanis et al., 2001). The finding was confirmed by another study using the same cell line which showed that chymotrypsin-like, trypsinlike and caspase-like activities of the proteasome were all decreased (Tanaka et al., 2001). Also, mutant $\alpha$-SYN increased cell death in the presence of a proteasome inhibitor. In M17 neuroblastoma cells, mutant $\alpha$-SYN (A30P or A53T) increased sensitivity to proteasome inhibitors by decreasing proteasome function measured by a GFP reporter system (Petrucelli et al., 2002). These studies indicated reduced proteasome function related to mutant $\alpha$-SYN, but not to wild-type. However, Snyder et al. (2003) showed inhibition of the proteasome with overexpressing wild-type $\alpha$-SYN in neuroblastoma M17 cells. A study with yeasts revealed impairment of proteasome-mediated protein degradation in cells expressing wild-type and mutant (A30P) $\alpha$-SYN (Chen et al., 2005). The cells expressing $\alpha$-SYN also exhibited a decrease in chymotrypsin-like activity, but no other proteolytic activity of the proteasome was altered.

Contrary to these studies, overexpression of wild-type or mutant (A30P, A53T) $\alpha$-SYN in PC12 cells or transgenic mice did not result in dysfunction of the UPP (Martin-Clemente et al., 2004). In a more recent study, Zondler et al. (2017) demonstrated that the impairment of proteasome activity by $\alpha$-SYN is dependent upon the cellular background. In this study, recombinant $\alpha$-SYN oligomers and fibrils in vitro or transient expression of wild-type or mutant (A30P, A53T) $\alpha$-SYN in U2OS ps 2042 [Ubi(G76V)-GFP] cells did not affect 20S proteasome function. In contrast, in DA SH-SY5Y and PC12 cells, stable expression of both wild-type and mutant $\alpha$-SYN resulted in impairment of the chymotrypsin-like 20S/26S proteasomal protein cleavage.

The proposed mechanisms of how $\alpha$-SYN inhibits the activity of the proteasome may be by direct binding to the $S 6^{\prime}$ or the Rpt5 subunit of the $19 \mathrm{~S}$ proteasome, or to the $\beta 5$ subunit of the 20S proteasome (Ghee et al., 2000; Snyder et al., 2003; Lindersson et al., 2004). In addition, different $\alpha$-SYN species have been implicated in UPP dysfunction. PC12 cells expressing wild-type or mutant $\alpha$-SYN produce soluble intermediate sized oligomers that associate with the $26 \mathrm{~S}$ proteasome and increase in amount after treatment with proteasomal inhibitor, indicating specific degradation of the $26 \mathrm{~S}$ proteasome (Emmanouilidou et al., 2010). In fact, the expression of $\alpha$-SYN leads to inhibition of all proteasome activities. This study suggested that only a subset of soluble cellderived $\alpha$-SYN oligomers are targeted to the $26 \mathrm{~S}$ proteasome for degradation. Simultaneously, these species can inhibit the proteasome function.

\section{The Autophagy-Lysosomal Pathway}

The ALP is responsible for degrading long-lived proteins, cellular components and organelles through the lysosomal compartment (Parzych and Klionsky, 2014). The ALP has two main purposes: to clear deleterious intracellular components and recycle macromolecules from organelles and proteins to guarantee proteome renewal. Depending on the delivery method, ALP can be divided into three pathways: macroautophagy, chaperonemediated autophagy (CMA) and microautophagy (Figure 1B). Because of the lack of evidence linking microautophagy to $\alpha$-SYN, the focus here is on macroautophagy and CMA.

Macroautophagy is an evolutionary and highly conserved process and the best known of the three autophagic mechanisms (Parzych and Klionsky, 2014; Bento et al., 2016). After the discovery of autophagy-related genes (Atg), the molecular pathway of macroautophagy has been well-characterized. Macroautophagy involves the formation, elongation, and nucleation of double-membrane organelles called autophagosomes that sequester the substrate before fusion with lysosomes. CMA is a particular system based on the recognition of a specific amino acid sequence (KFERQ) (Dice, 1990). The cytosolic chaperone heat shock cognate protein of $70 \mathrm{kDa}$ (hsc70) recognizes the specific motif and translocates the substrate into the lysosome membrane where it interacts with the lysosome-associated membrane protein type $2 \mathrm{~A}$ (LAMP2A) (Cuervo and Dice, 1996). The final step of the translocation requires the presence of lysosome-associated hsc70 (lys-hsc70) which disassembles LAMP2A into monomers and initiates a new cycle of substrate uptake and degradation (Agarraberes et al., 1997).

Several genetic factors related to $\mathrm{PD}$ are involved or interact with ALP (Gan-Or et al., 2015). Mutations in GBA1 that encode the lysosomal hydrolase GCase can lead to lysosomal dysfunction and disruption of autophagy. For example, SCARB2, which encodes the lysosomal integral membrane protein type 2 and interacts with GCase, has been associated with a reduced risk for PD (Gan-Or et al., 2015). Mutations in the ATP13A2 (PARK9) gene, encoding a lysosomal ATPase, causes Kufor-Rakeb syndrome, a rare form of atypical, juvenile-onset autosomal recessive parkinsonism with pyramidal neurodegeneration and dementia.

Along with mutations in genes coding for lysosomal components, other PD-related mutations have been implicated in the process of autophagy. Mutations in the gene encoding vacuolar protein sorting-associated protein 35 (VPS35) cause a rare form of autosomal dominant PD (Gan-Or et al., 2015). VPS35 is involved in endosomal-lysosomal trafficking which is associated with autophagy. Several autosomal recessive PD genes, like parkin (PARK2), PINK1 (PARK6), DJ-1 (PARK7), and FBXO7 (PARK15) have been linked to mitophagy, the process of degradation of dysfunctional mitochondria by autophagy (Burchell et al., 2013; Gan-Or et al., 2015; Pickrell and Youle, 2015). Mutations in $L R R K 2$ are the most common known genetic causes for PD. LRRK2 can be degraded by macroautophagy and CMA, but the most common mutation, G2019S, is poorly degraded by this pathway (Orenstein et al., 2013). In addition, mutated LRRK2 impaired CMA leading to an accumulation of other CMA substrates, including $\alpha$-SYN. Moreover, mutant LRRK2 caused an increase of autophagic vacuoles in a neuronal cellular model, proposing a more general role of LRRK2 in autophagy (Plowey et al., 2008). In a recent study, Ho et al. (2018) showed that LRRK2 mediates phosphorylation of leucyl-tRNA synthetase leading to impairment of autophagy. 
After the initial finding of accumulation of autophagic vacuoles in the SN of PD patients (Anglade et al., 1997), several pathological studies suggested that macroautophagy and CMA are deregulated along with several key proteins related to macroautophagy. Increased levels of beclin-1, which is responsible for the formations and maturation of autophagosomes, and increased levels of autophagosome marker LC3II have been found in the SN of PD patients (Dehay et al., 2010; Miki et al., 2016). Likewise, decreased levels of lysosomal-associated membrane protein type 1 (LAMP1) were evident in nigral neurons in PD patients (Chu et al., 2009; Dehay et al., 2010). The impairment of CMA is associated with the pathogenesis of PD since chaperone Hsc70 and LAMP2 were less expressed in several structures of PD brains (Alvarez-Erviti et al., 2010; Murphy et al., 2015). Decreased levels of several lysosomal markers have been shown in the SN of PD patients. These include the structural protein LAMP1 (Dehay et al., 2010), the lysosomal P-type ATPase ATP13A2 (Dehay et al., 2012), GCase (Gegg et al., 2012; Murphy et al., 2014) and heat shock protein 73 (Chu et al., 2009). In addition, altered activities of lysosomal enzymes, like GCase, Cathepsin A and D have been detected in PD brains (Chu et al., 2009; Gegg et al., 2012; Murphy et al., 2014; Chiasserini et al., 2015).

Transcriptome studies have revealed deregulation of the ALP in PD brains and alterations of several autophagy-related processes, including mTOR, PI3K/AKT, and 14-3-3 protein signalings (Elstner et al., 2011; Mutez et al., 2014; Dijkstra et al., 2015). Increased levels of mTOR protein expression were found in the temporal cortex of patients with DLB, in particular in neurons displaying $\alpha$-SYN accumulation (Crews et al., 2010). The alteration of other upstream autophagy-related proteins has also been demonstrated, including the immunoreactivity of UNC-51like kinase 1 (ULK-1), ULK-2, VPS35 and autophagy/Beclin-1 regulator 1 (AMBRA1) within mature LBs, increased levels of Beclin-1, and changed subcellular localization of transcription factor EB (TFEB) (Decressac and Bjorklund, 2013; Miki et al., 2016). Moreover, in a recent study a downregulation of 6 core autophagy genes (ULK 3, Atg2A, Atg4B, Atg5, Atg16L1, and histone deacetylase 6), and increased protein levels of ULK1, Beclin1, and AMBRA1 were detected in peripheral blood mononuclear cells (PBMCs) of PD patients (Miki et al., 2018). These protein levels correlated with increased $\alpha-S Y N$ levels in PBMCs. These results suggest a decrease in autophagy properties in PD patients.

\section{The autophagy-lysosomal pathway and $\alpha-S Y N$}

While $\alpha$-SYN can be cleared by UPP, the main pathway for its degradation appears to be lysosomal (Webb et al., 2003; Vogiatzi et al., 2008). $\alpha$-SYN can be degraded by both macroautophagy and CMA, but the structure and mutations may change the final path of degradation. Small soluble forms of $\alpha$-SYN are more likely to be degraded by CMA but in the pathological condition the burden shifts to macroautophagy even though both pathways can compensate for each other.

Induction of autophagy with rapamycin leads to the clearance of overexpressed wild-type and mutant $\alpha$-SYN in cell cultures (Webb et al., 2003). This study established that inhibition of macroautophagy with 3-methyladenine causes the accumulation of mutant - but not wild-type - $\alpha$-SYN. In contrast, a study with PC12 cells showed an increase in both endogenous and overexpressed wild-type $\alpha$-SYN when macroautophagy was inhibited with 3-methyladenine (Vogiatzi et al., 2008). Other studies with neuronal cells or transgenic mice overexpressing wild-type $\alpha$-SYN showed accumulation of $\alpha$-SYN only upon general lysosomal inhibition, and not in suppressed macroautophagy (Lee et al., 2004; Klucken et al., 2012). However, another study has revealed an increase of A53T $\alpha$-SYN oligomers after pharmacological or molecular inhibition of macroautophagy (Yu et al., 2009). Conditional depletion of Atg7 in DA neurons caused age-related neuronal loss, the formation of ubiquitinated protein aggregates and increase in monomeric $\alpha$-SYN (Ahmed et al., 2012). In addition, $\alpha$-SYN aggregates were detected in striatal axonal swellings of 20-monthold mice after depletion of Atg7 (Friedman et al., 2012). Both studies suggested a role of macroautophagy in $\alpha$-SYN turnover in vivo, since macroautophagy impairment caused modest alterations in endogenous $\alpha$-SYN. Overall, these studies indicate that degradation of $\alpha-S Y N$ by macroautophagy may depend on the conformation of $\alpha$-SYN. It is likely that small amounts of wild-type $\alpha$-SYN are degraded by CMA, but in cases of overexpression or mutations, macroautophagy becomes a more important pathway. The macroautophagic degradation of $\alpha$-SYN could also depend on PTMs. Phosphorylation and SUMOylation [Small Ubiquitin-like Modifier (SUMO)] have been reported to increase $\alpha$-SYN degradation by macroautophagy in yeast and PD models (Oueslati et al., 2013; Shahpasandzadeh et al., 2014; Tenreiro et al., 2014). Inside the lysosome, $\alpha-S Y N$ is mainly degraded by Cathepsin D, and overexpression of the mutant form of this protease leads to increased levels of $\alpha$-SYN (Crabtree et al., 2014). In addition, Cathepsin D knockout mice exhibited an accumulation of higher molecular weight $\alpha$-SYN species (Cullen et al., 2009). Overexpression of mutant A53T $\alpha$-SYN has been reported to enhance autophagic flux which causes increase in autophagic vacuoles and macroautophagic degradation (Cuervo et al., 2004; Xilouri et al., 2009; Choubey et al., 2011). Similar effects have been reported with wild-type $\alpha$-SYN, although to a lesser extent. $\alpha$-SYN can also inhibit macroautophagy via interaction with Rab proteins leading to Atg9 mislocalization (Winslow et al., 2010). Furthermore, $\alpha$-SYN has been shown to enhance mitophagy. In a transgenic mouse model expressing A53T specifically in DA neurons, the induction of mitophagy was detected (Chen et al., 2015). In the cell culture model, $\alpha$-SYN overexpression caused increased mitophagy leading to neuronal death (Choubey et al., 2011). However, elevated macroautophagic flux was evident in primary midbrain neurons overexpressing wild-type and A53T $\alpha$-SYN, without significant alterations in mitophagy (Koch et al., 2015).

Besides neuronal cells, the relation of $\alpha-S Y N$ and autophagy has also been demonstrated in other cell types. DJ-1 knockdown microglia exhibited an impaired uptake of $\alpha-S Y N$ and had lower autophagy-dependent degradation of p62 and LC3 proteins (Nash et al., 2017). In immortalized astrocyte cell lines overexpressing wild-type, A30P and A53T mutant $\alpha$-SYN showed decreased LC3-II and increased p62 protein levels, suggesting the 
inhibition of autophagy (Erustes et al., 2018). In addition, iPSCderived astrocytes with LRRK2 G2019S mutation accumulated $\alpha$-SYN and had impaired macroautophagy and dysfunctional CMA (di Domenico et al., 2019). PD astrocytes displayed LAMP2A positive vesicles all around the cell body, whereas in control lines the vacuoles were in the perinuclear area. In addition, $\alpha$-SYN co-localized with LAMP2A receptor in PD astrocytes. LAMP1 -positive vesicles were also found throughout the cell in PD astrocytes, and there was an increase in autophagic vacuoles. Furthermore, higher basal levels of LC3-II, p62 and impaired autophagic flux were detected from PD astrocytes.

The link between $\alpha$-SYN and CMA was initially established in purified lysosomes demonstrating that $\alpha$-SYN could be actively degraded by CMA (Cuervo et al., 2004). Interestingly, A30P and A53T $\alpha$-SYN mutations had higher affinity to LAMP2A and blocked and totally impaired the CMA pathway. Since then, the higher affinity of the mutant $\alpha$-SYN to LAMP2A was confirmed in neuronal cultures and other cell culture models (Vogiatzi et al., 2008; Alvarez-Erviti et al., 2010). In the neuronal systems, the inhibition of CMA leads to the formation of high molecular weight or detergent-insoluble oligomeric $\alpha$-SYN conformations (Vogiatzi et al., 2008). Also, in mice where $\alpha$-SYN expression was enhanced with paraquat or transgenic overexpression, the intralysosomal content of $\alpha$-SYN was increased as well (Mak et al., 2010). The overexpression of $\alpha$-SYN in mice also led to upregulation of LAMP2A and hsc70. Another study with mice with VPS35 deficiency or expression of PD-linked mutation D620N showed accumulation of $\alpha-S Y N$ in DA neurons and DA degeneration (Tang et al., 2015). This was accomplished by an impaired endosome-to-Golgi retrieval of LAMP2A leading to decreased levels of LAMP2A and a reduced $\alpha$-SYN clearance. In Drosophila, which lacks CMA, neuronal expression of human LAMP2A protected against starvation and oxidative stress and delayed the locomotor decline in aging flies (Issa et al., 2018). LAMP2A also alleviated the progressive locomotor and oxidative defects induced by neuronal expression of PDassociated human A30P $\alpha$-SYN. LAMP2A stimulated autophagy in adult Drosophila, and neuronal expression of LAMP2A upregulated levels of Atg5.

PTMs can affect the degradation of $\alpha$-SYN through CMA. Oxidation and nitration of $\alpha$-SYN slightly inhibited the CMA, whereas phosphorylation and exposure to dopamine almost completely block the CMA degradation system. However, only dopamine-modified $\alpha$-SYN blocks the degradation of other substrates (Martinez-Vicente et al., 2008). The same study reported that CMA could degrade only monomeric or dimeric $\alpha$-SYN, but not oligomers. Blocking the CMA by aberrant forms of $\alpha$-SYN can also have a toxic effect and impact other degradation pathways. PD-linked mutations like A30P and A53T or dopamine-modified wild-type $\alpha$-SYN can inhibit the function of CMA leading to activation of macroautophagy and increased toxicity in cells (Martinez-Vicente et al., 2008; Xilouri et al., 2009).

Recently, micro-RNAs (miRNAs) have been implicated in CMA function and $\alpha$-SYN clearance. Several miRNAs have been described to target LAMP2A and Hsc70 and decrease $\alpha$-SYN degradation (Alvarez-Erviti et al., 2013; Li et al., 2014). The initial study found four miRNAs that reduce LAMP2A levels, and three that decreased Hsc70 levels. This was accompanied by increased accumulation of $\alpha$-SYN in SH-SY5Y neuroblastoma cells. These miRNAs were also found up-regulated in brains of PD patients and correlated with decreased protein levels of CMA (Alvarez-Erviti et al., 2013).

\section{Autophagy enhancing agents as a potential therapeutic strategy for $P D$}

Because ALP is an important pathway in $\alpha$-SYN degradation, the opportunity to use autophagy enhancement as a strategy against $\alpha$-SYN aggregation in PD has raised considerable interest. Pioneering studies with rapamycin and other macroautophagy enhancing agents have demonstrated an increased $\alpha$-SYN clearance in several PD models. However, the selectivity of these early autophagy enhancers is limited. Selective targeting of ALP components, like TFEB, lysosomes, and CMA, may provide more potential for development of new therapies for PD. The main findings are listed in Table 1, and for more details see the literature (Moors et al., 2017).

The most studied and used macroautophagy-enhancer is rapamycin which inhibits mTORC1 signaling (Bové et al., 2011). Rapamycin has been shown to reduce $\alpha$-SYN accumulation in wild-type, A30P, or A53T $\alpha$-SYN expressing PC12 cells and in mice (Crews et al., 2010) and rats (Decressac and Bjorklund, 2013) with overexpressed $\alpha$-SYN. Rapamycin also improved the motor function in mice with overexpressed A53T $\alpha$-SYN (Bai et al., 2015). The drawback of mTORC1 inhibition is the interference with numerous other pathways. Prolonged treatment with rapamycin can inhibit mTORC2 and stimulate other cellular pathways, including cell survival mechanisms (Bové et al., 2011). The activation of macroautophagy can be achieved by activating AMPK, leading to downstream inhibition of mTORC1. Several agents which act through this pathway have been described, such as metformin, 5-aminoimidazole-4carboxamide ribonucleotide (AICAR) and resveratrol (Curry et al., 2018). Metformin, commonly used to treat Diabetes Mellitus, showed neuroprotective effects in in vitro and in vivo models of PD ( $\mathrm{Ng}$ et al., 2013; Dulovic et al., 2014; Patil et al., 2014). Metformin also decreased phosphorylated levels of $\alpha$-SYN in SH-SY5Y cells and MPTP-treated mice (PérezRevuelta et al., 2014; Katila et al., 2017). Another agent that affects the AMPK signaling is trehalose, which inhibits members of the SLC2A (GLUT) family of glucose transporters leading to AMPK-dependent increase of macroautophagy (DeBosch et al., 2016). Trehalose-induced autophagy has shown to increase cell survival and $\alpha-S Y N$ clearance in cell lines and in multiple in vivo models (Sarkar et al., 2007, 2014; Rodríguez-Navarro et al., 2010; Lan et al., 2012; Tanji et al., 2015; He et al., 2016). However, a recent study did not find improvement in neuronal survival after exposure to $\alpha$-SYN pre-formed fibrils (Redmann et al., 2017). Although increasing autophagy by AMPK pathway has shown beneficial effects, AMPK is involved in several other cellular functions, and its modulation is likely to induce unwanted effects.

Recently, several other agents acting through an mTORdependent pathway have been studied in cell cultures and PD animal models. Sheng et al. (2017) showed that uric acid treatment increased autophagy in PC12 cell in dose- and 
TABLE 1 | Commonly used autophagy enhancing agents.

\begin{tabular}{|c|c|c|c|c|c|}
\hline & Target & Agent & PD model & Effect & References \\
\hline \multirow[t]{25}{*}{ Autophagy } & mTORC1 & & $\alpha$-SYN overexpressed SH-SY5Y & $\downarrow$ Phospho-Ser129 $\alpha$-SYN levels & Pérez-Revuelta et al., 2014 \\
\hline & & analogs & Rotenone-exposed SH-SY5Y cells & $\downarrow$ Cell death, $\downarrow$ Mitochondrial dysfunction & $\begin{array}{l}\text { Pan et al., 2009; Xiong et al., } \\
\text { 2011; Hou et al., } 2015\end{array}$ \\
\hline & & & 6-OHDA and MPTP treated PC12 & $\downarrow$ Cell death & Malagelada et al., 2010 \\
\hline & & & MPTP mice & $\downarrow$ Cell death & $\begin{array}{l}\text { Dehay et al., 2010; Malagelada } \\
\text { et al., } 2010\end{array}$ \\
\hline & & & $\alpha \alpha-S Y N$ transgenic mice & $\downarrow$ Cell death & Crews et al., 2010 \\
\hline & & & $\alpha$-SYN transgenic rats & $\downarrow$ Cell death & Decressac et al., 2013 \\
\hline & & & A53T $\alpha$-SYN transgenic mice & $\downarrow$ Cell death & Bai et al., 2015 \\
\hline & & & 6-OHDA mice & $\downarrow$ Levodopa-induced dyskinesia & Santini et al., 2009 \\
\hline & & & 6-OHDA rats & $\downarrow$ Levodopa-induced dyskinesia & Decressac and Bjorklund, 2013 \\
\hline & AMPK & Metformin & MPTP mice & $\downarrow$ Cell death, $\alpha$-SYN levels & Katila et al., 2017 \\
\hline & & & & $\uparrow$ Neurotrophic factors & \\
\hline & & & $\alpha$-SYN overexpressed SH-SY5Y & $\downarrow$ Phospho-Ser129 a-SYN levels & Pérez-Revuelta et al., 2014 \\
\hline & Beclin-1 & PREP inhibitor & A30P $\alpha$-SYN transgenic mice & $\downarrow$ Oligomeric $\alpha$-SYN, $\uparrow$ Striatal DA levels & Savolainen et al., 2014 \\
\hline & & Isorhynchophylline & $\begin{array}{l}\text { N2a cells transfected with WT, } \\
\text { A53T and A30P } \alpha \text {-SYN }\end{array}$ & $\uparrow \alpha$-SYN clearance & Lu et al., 2012 \\
\hline & & & Embryonic DA neurons & $\uparrow \alpha$-SYN clearance & Lu et al., 2012 \\
\hline & & & $\begin{array}{l}\text { WT, A30P, and A53T } \alpha-S Y N \\
\text { expressing PC1 } 2 \text { cells }\end{array}$ & $\begin{array}{l}\uparrow \alpha \text {-SYN clearance, } \downarrow \alpha \text {-SYN } \\
\text { accumulation }\end{array}$ & Webb et al., 2003 \\
\hline & & & $\alpha$-SYN transgenic mice & $\begin{array}{l}\uparrow \alpha \text {-SYN clearance, } \downarrow \alpha \text {-SYN } \\
\text { accumulation }\end{array}$ & Miki et al., 2016 \\
\hline & TFEB & $2-\mathrm{HP} \beta C D$ & $\begin{array}{l}\text { Human neuroglioma cells } \\
\text { transfected with } \alpha \text {-SYN }\end{array}$ & $\uparrow \alpha$-SYN clearance & Kilpatrick et al., 2015 \\
\hline & SLC2A & Trehalose & Rotenone-treated rats & $\downarrow$ Cell loss & \\
\hline & & & Rotenone-treated PC12 cells & $\downarrow$ Cell loss, $\uparrow \alpha$-SYN clearance & Wu et al., 2015 \\
\hline & & & M MPTP mice & $\begin{array}{l}\downarrow \text { Cell loss, } \downarrow \text { Neuroinflammation, } \\
\downarrow \text { Motor deficits }\end{array}$ & Sarkar et al., 2014 \\
\hline & & & A53T $\alpha$-SYN overexpression in rats & $\begin{array}{l}\downarrow \text { Cell loss, } \downarrow \text { Motor deficits, } \uparrow \alpha \text {-SYN } \\
\text { clearance }\end{array}$ & He et al., 2016 \\
\hline & & & $\begin{array}{l}\text { WT and A53T } \alpha \text {-SYN expressed } \\
\text { PC12 cells }\end{array}$ & $\uparrow \alpha$-SYN clearance & $\begin{array}{l}\text { Sarkar et al., 2007; Lan et al., } \\
2012\end{array}$ \\
\hline & & & NB69 human neuroblastoma cells & $\uparrow \alpha$-SYN clearance & Casarejos et al., 2011 \\
\hline & & & A53T $\alpha$-SYN overexpressing mice & $\uparrow$ Detergent-insoluble $\alpha$-SYN clearance & Tanji et al., 2015 \\
\hline \multirow[t]{3}{*}{ Lysosomes } & GCase & Ambroxol & GBA1 mutant fibroblasts & $\begin{array}{l}\uparrow \text { Lysosomal function, } \uparrow \text { GCase activity } \\
\downarrow \text { Oxidative stress }\end{array}$ & $\begin{array}{l}\text { McNeill et al., 2014; Ambrosi } \\
\text { et al., } 2015\end{array}$ \\
\hline & & & Primary cortical neurons & $\uparrow$ GCase activity, $\uparrow$ TFEB & Magalhaes et al., 2018 \\
\hline & & & $\alpha \alpha$-SYN transgenic mice & $\uparrow$ GCase activity, $\downarrow \alpha$-SYN levels & Migdalska-Richards et al., 2016 \\
\hline
\end{tabular}

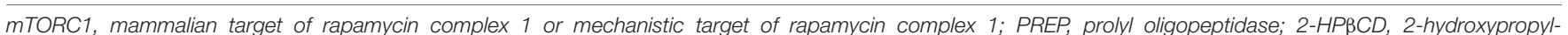

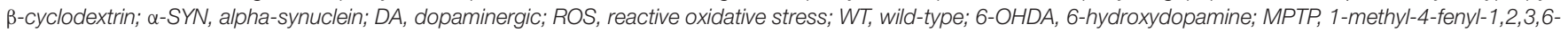
tetrahydropyridine; Gcase, glucocerebrosidase; TFEB, transcription factor EB; SLC2A, (GLUT) family of glucose.

time-dependent manners. Moreover, uric acid reduced $\alpha$-SYN accumulation in PC12 cells overexpressing wild-type or A53T mutant $\alpha-S Y N$. In vivo, uric acid modulated autophagy markers increased the autophagosome/autolysosome formation and reduced $\alpha$-SYN accumulation in the midbrain of SNCA A53T transgenic mice. Suresh et al. (2017) showed that a novel autophagy modulator 6-Bio alleviated $\alpha$-SYN toxicity. In yeast and mammalian cell lines, 6-Bio induced autophagy and enhanced autolysosome formation which resulted in $\alpha-S Y N$ degradation and clearance. In vivo studies with a MPTP mouse model demonstrated that 6-Bio has a neuroprotective activity, enhances autophagy and clearance of toxic protein aggregates and ameliorates MPTP-induced behavioral deficits.
The results demonstrated that 6-Bio modulates autophagy in a GSK3B-dependent manner and the induction of autophagy in mammalian cells appears to be mTOR dependent.

Instead of general activation of macroautophagy, targeting selective ALP components including Beclin-1, TFEB, and lysosomes have been tried. Activation of Beclin-1 induces autophagosome formation and initiation of autophagy. Overexpression of Beclin-1 has been shown to reduce accumulation of $\alpha-S Y N$ in PC12 cells and mice with overexpressed $\alpha$-SYN (Spencer et al., 2009; Wang et al., 2016). In addition, the drug-induced activation of Beclin-1 has been demonstrated to increase autophagy and promotes $\alpha$-SYN clearance in neuronal cell lines and PD animal models (Lu et al., 
2012; Savolainen et al., 2014). One attractive target to stimulate macroautophagy downstream of mTORC1 is modulating transcriptional levels of TFEB. TFEB regulates macroautophagy and lysosomes and acts as a link between upstream signaling pathways (Settembre et al., 2011). Overexpression of TFEB eliminated $\alpha$-SYN oligomers and rescued midbrain DA neurons from $\alpha$-SYN toxicity in overexpressing rats (Decressac and Bjorklund, 2013). Another strategy for stimulating ALP in $\mathrm{PD}$ is a direct modulation of lysosomes. The potential of targeting the lysosome system has been demonstrated with acidic nanoparticles which were able to stimulate lysosomal degradation and revert the lysosomal dysfunction in genetic PD models (Baltazar et al., 2012; Bourdenx et al., 2016). Ambroxol, AT2101 (isofagomine) and histone deacetylase inhibitors can correct the folding of GCase and therefore increase the GCase and lysosome function (Blanz and Saftig, 2016). The small-molecule chaperones have been demonstrated to enhance GCase activity, improve lysosomal function and enhance $\alpha-S Y N$ clearance in preclinical models of PD (Steet et al., 2006; Khanna et al., 2010; Sun et al., 2012; Yang et al., 2013; McNeill et al., 2014; Richter et al., 2014; Ambrosi et al., 2015). Especially ambroxol is widely studied presently. In mice overexpressing $\alpha$-SYN or heterozygous L444P mutation in $C B A 1$, ambroxol treatment increased the GCase activity while decreasing phosphorylated and endogenous levels of $\alpha$-SYN (Migdalska-Richards et al., 2016, 2017b). In non-human primates, ambroxol increased brain GCase activity (Migdalska-Richards et al., 2017a). In patients with Gaucher disease, ambroxol was able to cross the blood-brain barrier and high-dose oral administration was safe and well-tolerated (Narita et al., 2016).

Currently, ambroxol is in phase II clinical trials tested for treatment of PD and PD with dementia (ClinicalTrials.gov Identifier: NCT02941822 and NCT02914366, respectively) (Silveira et al., 2019).

Downstream targeting of the CMA components presents an alternative approach to develop new strategies for PD. Induced overexpression of LAMP2A in human SH-SY5Y cells, rat primary cortical neurons in vitro and nigral DA neurons in vivo decreased $\alpha$-SYN accumulation and protected $\alpha$-SYNinduced DA degeneration (Xilouri et al., 2013). Retinoic acid alpha receptors have been identified as CMA inhibitors, and synthetic derivatives of all-trans-retinoic acid were developed to reverse this effect (Anguiano et al., 2013). These derivates specifically stimulated CMA and LAMP2A was identified as one of the targets.

\section{ROLE OF ER STRESS IN PD AS A RESULT OF DYSFUNCTIONAL CELLULAR PROTEOSTASIS}

Endoplasmic reticulum is the first component of the secretory pathway mainly responsible for protein synthesis, posttranslational processing and folding of newly synthesized proteins. The proteins are then transported to their final destinations in membrane-bound vesicles. Disturbance in any of these functions including proper folding capacity and disposal of misfolded proteins leads to ER stress and activation of intracellular signal transduction pathway that is essentially intended to re-establish ER homeostasis. These biological processes are collectively called the UPR. Inability to restore ER functions induces cell death via apoptosis. Growing evidence from studies in human PD post-mortem brain, additionally to genetic and neurotoxin models, suggests that ER stress is a common feature in PD that contributes to PD pathology. Recently, the generation of neuronal cultures from iPSCs derived from PD patients indicated that ER stress leads to the accumulation of ER-associated degradation (ERAD) substrates and placed this ER dysfunction as an early component of PD pathogenesis (Chung et al., 2013; Heman-Ackah et al., 2017).

\section{Causes of ER Stress in PD}

The ER is crucial for protein folding, trafficking to the Golgi, UPR, and calcium buffering. The imbalance between the load on ER functions and ER capacity leads to ER stress. In PD, the mechanisms leading to ER stress and the actual role of the UPR in degeneration of the DA neurons are the object of intensive research. Oligomeric $\alpha$-SYN has been shown to accumulate in the ER in animal models and PD patient brains (Colla et al., 2012). The aggregation of $\alpha$-SYN induces ER stress, which eventually results in inflammation and neurodegeneration.

A number of studies have shown that $\alpha$-SYN affects Rab1, a protein involved in trafficking components from the ER to the Golgi. Over-expression of Rabl in animal models of PD reduced stress levels and protected DA neurons against degeneration (Coune et al., 2012). Further, $\alpha$-SYN directly interacts with nascent activating transcription factor 6 (ATF6), effectively preventing its association with COPII vesicles that generally transfer proteins to the Golgi. This has specific implications: (1) interfering with the Rab1 protein could lead to accumulation of unfolded proteins in the ER, and (2) inhibition of ATF6 would generally stop the ERAD, triggering the cell to signal apoptosis (Credle et al., 2015). Other studies are linking $\mathrm{PD}$ genes with alteration of the secretory pathway, including LRRK2, Parkin, DJ-1, ATP13A2 (Mercado et al., 2013), and VPS35 (Zimprich et al., 2011), which may result in pathological levels of ER stress contributing to the etiology of the disease. Furthermore, increase in cytoplasmic $\mathrm{Ca}^{2+}$ levels induced by 6-hydroxydopamine (6-OHDA) (a toxin capable to generate, in vitro and in vivo, some features of $\mathrm{PD}$ associated neurodegeneration) was detected in 6-OHDA-treated rats. Pretreatment with ryanodine or ER stress inhibitor 4-PBA inhibited RyR receptor $\mathrm{Ca}^{2+}$ channels and protective midbrain DA neurons from degeneration (Huang et al., 2017).

\section{UPR Response in PD}

The primary function of the UPR is a maintenance of ER protein homeostasis. When cells undergo constant ER stress, the UPR is responsible for the elimination of damaged cells through apoptotic mechanisms, some of which appear to be specific to ER stress and others that are included in general apoptotic pathways (Xu et al., 2005). The activation of UPR depends on three ER stress sensors proteins, protein kinase RNA-like endoplasmic reticulum kinase (PERK) receptor, inositol-requiring enzyme 1 


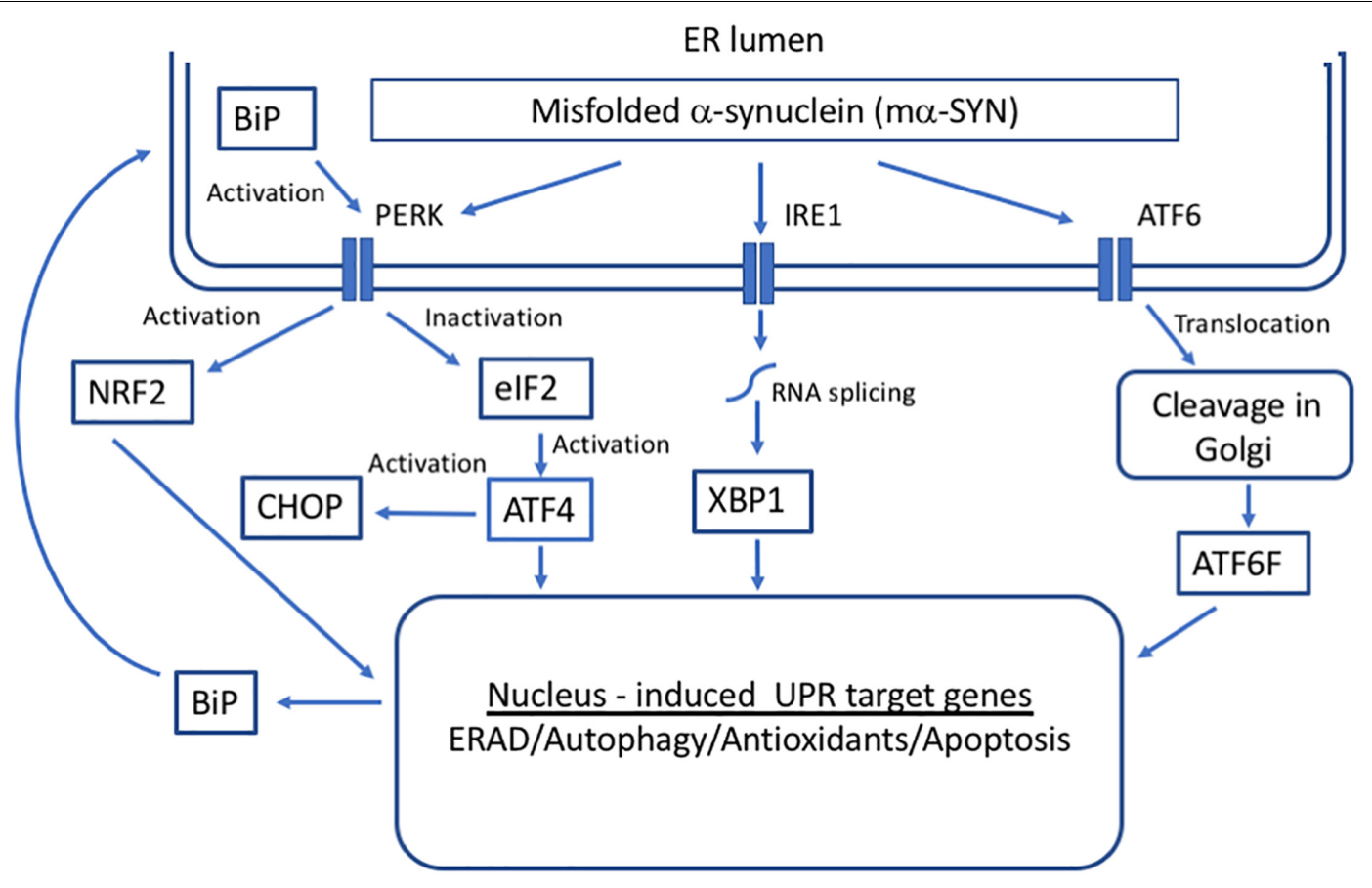

FIGURE 2 | Unfolded protein response (UPR) in response to alpha-synuclein misfolding. Three transmembrane proteins have been identified as sensors of unfolded proteins in the ER in mammalian cells: IRE1 (inositol-requiring protein 1), ATF6 (activating transcription factor 6), and PERK (protein kinase RNA-like ER kinase). Upon the accumulation of $\mathrm{m} \alpha$-SYN, BiP dissociates from UPR sensors inducing their activation that leads to the transcription of genes whose protein products increase the folding capacity of the cell.

(IRE1), and ATF6 (Schröder and Kaufman, 2005) (Figure 2). Under normal physiological conditions, all three effectors are negatively regulated by the ER chaperone glucose-regulated protein 78/ binding immunoglobulin protein (GRP78/BiP), which suppresses their activity by binding to their luminal ends (Bertolotti et al., 2000).

Under conditions of ER stress and increase in unfolded proteins, BiP dissociates from UPR sensors inducing their activation. Activation of the ER pathways helps to fight the cellular stress through the combined actions of suppressing the translation of new proteins, inducing ER chaperones that promote protein refolding and activating the proteasome to degrade misfolded/unfolded proteins. There is direct evidence that GRP78/BiP levels are increased in cell as well as animal models of PD forming a complex with $\alpha$-SYN (Bellucci et al., 2011). Moreover, it has been demonstrated that aging leads to a significant decline in GRP78/BiP expression (up to $40 \%$; Naidoo, 2009). However, under chronic ER stress, UPR sensors shift their signaling toward induction of cell death by apoptosis (Urra et al., 2013).

\section{PERK Signaling}

PERK is a type I ER transmembrane protein kinase with a luminal domain and a cytoplasmic domain that has kinase activity (Liu et al., 2002). Upon ER stress, BiP releases the luminal domain of PERK, which then dimerizes and autophosphorylates to become active (Harding et al., 1999). Following transautophosphorylation, this kinase phosphorylates the alpha subunit of eukaryotic initiation factor-2 (eIF2), inactivating it by Ser-51 phosphorylation and attenuating protein translation. This inhibitory effect of translation helps to alleviate ER stress by decreasing the overload of misfolded proteins and thereby protecting the cells under conditions where proteins cannot achieve proper folding (Fels and Koumenis, 2006). This event leads to activating transcription factor 4 (ATF4). The UPRrelated transcriptional factor ATF4 upregulates a subset of genes that control oxidative stress, metabolism, protein folding, and glutathione biosynthesis (Harding et al., 2000). Important targets of ATF4 include NRF2, which regulates the functions of a variety of antioxidant genes (He et al., 2001), and CHOP, which conversely is a key in the activation of apoptotic pathways and cell death (Han et al., 2013). In PD patients, the activation of PERK/ATF4 signaling is observed in different brain areas. $\alpha-S Y N$ has been shown to accumulate within the ER of nigral DA cells, directly activating the PERK/eIF $2 \alpha$ signaling and increasing the expression of ATF4 (Bellucci et al., 2011). The activation of this pathway overlapped with pro-apoptotic changes.

Further evidence supporting this pathway comes from PDassociated gene studies. By inducing the A53T $\alpha$-SYN mutation to PC12 cells, UPR activates CHOP and GRP78/BiP by increasing their expression and increases the phosphorylation of eIF2 $\alpha$ (Smith et al., 2005). Interventions to block ER stress and caspase activity using inhibitors, and to knock down the expression of caspase-12 using siRNA, protected against A53T $\alpha$-SYN induced cell death (Smith et al., 2005). In PINK1- and Parkinassociated PD models, mitofusins cause enhanced ER stress 
signaling, by interconnecting damaged mitochondria to the ER membranes (Celardo et al., 2016). PERK signaling inhibition, either pharmacological or genetic suppression, was beneficial in these experimental models of PD (Celardo et al., 2016). LRRK2 mutations also cause familial PD by accumulation and aggregation of $\alpha-S Y N$ and ubiquitinated proteins over time mainly due to the impairment of protein degradation pathways (Tong et al., 2010). This is likely to result in the buildup of unfolded proteins leading to ER stress, although there is little evidence of UPR activation yet. On the other hand, studies with GBA1 gene mutations revealed that treatment with chemical chaperones (ambroxol and isofagomine) can combat $G B A$-mediated ER stress by increasing $G B A$ levels and activity in fly models and in fibroblasts from PD patients (Sanchez-Martinez et al., 2016). In rodent models of PD, ATF4 upregulation in DA neurons of $\mathrm{SN}$ resulted in severe nigrostriatal degeneration caused by activating caspase 3/7dependent pathway (Gully et al., 2016). On the other hand, Grp78/BiP over-expression exerted neuroprotective effects in a rat model of PD (Gorbatyuk et al., 2012).

\section{IRE1 Signaling}

IRE1 is a type I ER transmembrane sensor and cell fate executor. IRE1 gets activated in response to the accumulation of misfolded proteins by autophosphorylation. The activation induces RNase activity that is consequently needed for unconventional splicing of X-box binding protein 1 (XBP1) (Calfon et al., 2002).
Spliced XBP1 translocates to the nucleus where it commands transcription of genes responsible for quality control, protein folding, lipid synthesis and ERAD pathway (Sriburi et al., 2004). In $\mathrm{PD}, \mathrm{XBP} 1$ controls the survival of DA neurons (Valdés et al., 2014). The developmental ablation of XBP1 preconditions DA neurons against the effect of the neurotoxin, 6-OHDA (Mollereau et al., 2014, 2016). The effect is specific to SNpc, as it is not seen in other brain regions. Contrary, reduction of XBP1 in DA neurons of adult mice caused ER stress with CHOP induction leading to degeneration (Valdés et al., 2014), highlighting the critical role of XBP1 depending on the development stage. In addition, a gene therapy approach using adeno-associated viral vectors to deliver XBP1 active form to the $\mathrm{SNpc}$ confers protection of DA neurons against 6-OHDA-mediated toxicity (Valdés et al., 2014). Moreover, XBP1 transgene delivered to mouse striatum using recombinant adenoviral vectors protected DA neurons against MPTP-induced degeneration (Sado et al., 2009). XBP1 is also protective when it is delivered in neural stem cells transfected with this transcription factor resulting in increased survival and improved behavior in a rotenone-induced rat model of PD (Si et al., 2012). Among other functions, XBP1 and ATF6 mediate the transcription of BiP. While the overexpression of this chaperone protects DA neurons and increases motor performance in a rat model of $\mathrm{PD}$, the age-related decline in $\mathrm{BiP}$ expression as well as siRNA-mediated downregulation, increases DA neuron vulnerability to $\alpha-S Y N$ in the same PD model (Salganik et al., 2015).

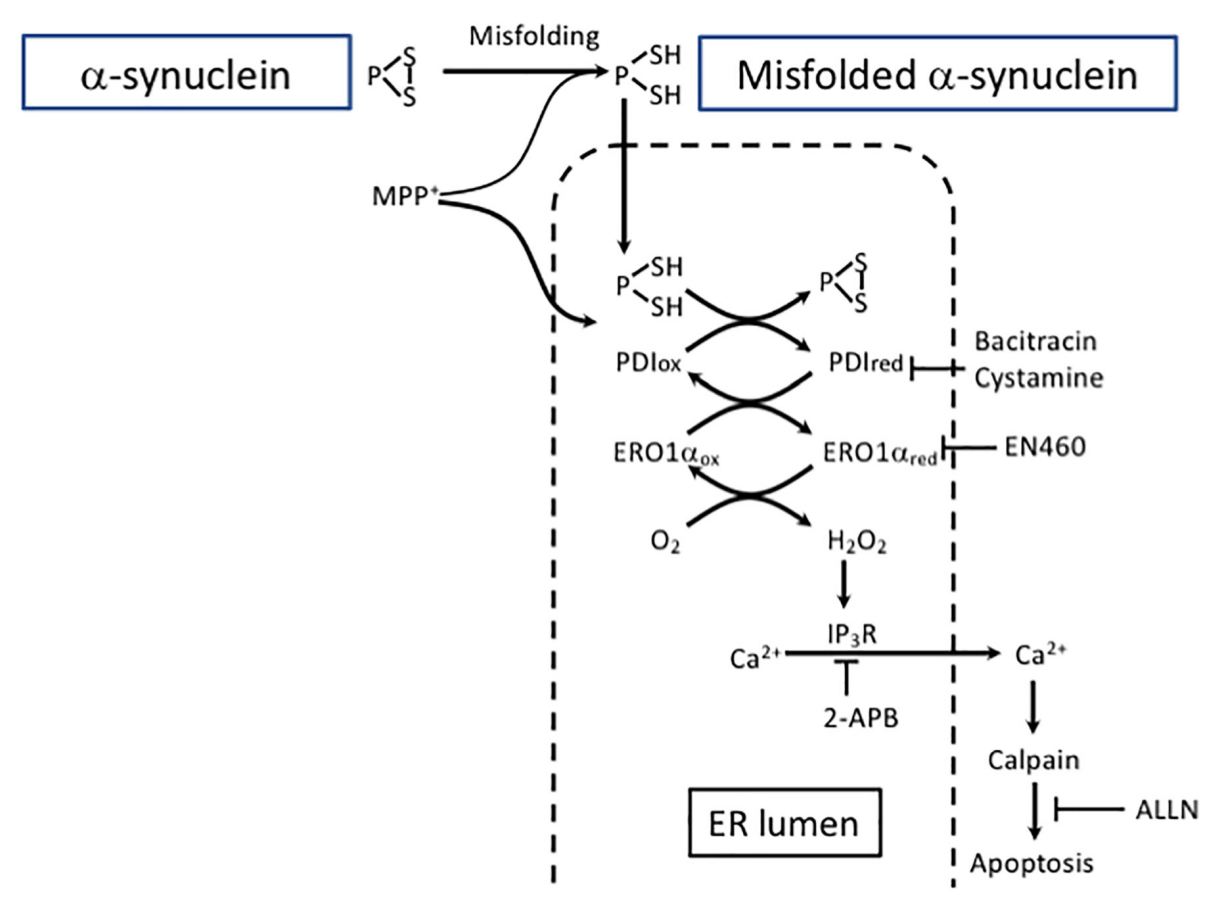

FIGURE 3 | Excessive protein refolding in ER leads to oxidative stress and apoptosis. Depending on the structure, aggregates can be degraded either by macroautophagy or CMA. Alternatively, misfolded $\alpha$-SYN undergoes refolding in the ER. However, excessive refolding upregulates PDI reduction. Re-oxidation of PDI is linked with an increase in hydrogen peroxide generation causing dysregulation of IP3R permeability and an increase in cytosolic calcium. Calcium release from the ER may activate calpain and eventually lead to apoptosis. The pharmacological inhibition of PDI by bacitracin or cystamine prevents ER redox imbalance and downstream proapoptotic events. The inhibition of the ERO1 catalyzed re-oxidation of PDI by EN460 results in a protective effect similar to PDI inhibitor. 


\section{ATF6 Signaling}

ATF6 is a type II ER transmembrane protein. Upon the accumulation of misfolded proteins in the ER, ATF6 moves to the Golgi apparatus where it is cleaved by two proteases (Haze et al., 1999). The cytosolic domain of ATF6 is translocated to the nucleus where it activates the transcription of ER chaperones (Gotoh et al., 2002). Contrarily, reduced levels of ATF6 in the nucleus of cells due to the impairment in ATF6 trafficking to the Golgi are likely to trigger apoptosis (Credle et al., 2015). In PD, $\alpha$-SYN directly targets ATF6 and inhibits ATF6 processing leading to an impaired up-regulation of ERAD genes, which sensitizes cells to apoptosis (Credle et al., 2015). In ATF $6 \alpha$ knockout animals, the accumulation of ubiquitin-positive inclusions and enhanced loss of DA neurons induced by MPTP, a PD-triggering neurotoxin, was detected (Egawa et al., 2011). This suggests that activation of the UPR has an important adaptive function to maintain protein homeostasis in this model. ATF6 mainly controls the levels of $\mathrm{BiP}$ and ERAD elements rather than development and survival of DA neurons in mice under resting conditions (Egawa et al., 2011).

\section{SUPPRESSION OF EXCESSIVE PROTEIN OXIDATIVE FOLDING AS AN ALTERNATIVE SOLUTION FOR LOWERING ER STRESS}

As indicated above, ER stress is increasingly implicated in $\mathrm{PD}$, and emerging evidence highlights the complexity of the UPR, with both protective and detrimental components being described. Mild insults increase the activity of chaperones, such as protein disulfide isomerase (PDI) that is responsible for the oxidative folding through formation of disulfide bonds in proteins (Rao and Bredesen, 2004). To promote correct disulfide bond formation in unfolded/misfolded proteins, the redox environment in the ER is oxidatively maintained (Hwang et al., 1992). In neurons, the increased activity of PDI represents an adaptive response that is induced to protect the cells (Haynes et al., 2004). In contrast, recent studies have revealed alternative roles for PDI in neurodegenerative diseases (Hoffstrom et al., 2010; Lehtonen et al., 2016).

In PD, ER homeostasis is disrupted in DA neurons in $\mathrm{SNpc}$ and PDI co-localizes with $\alpha-S Y N$ in LBs (Conn et al., 2004). We have recently demonstrated that treatment with 1 methyl-4-phenylpyridinium (MPP+), a neurotoxin associated with PD, upregulated the expression of $\alpha$-SYN and PDI in human neuroblastoma SH-SY5Y cells and that $\alpha$-SYN co-localized with PDI. The $\alpha-S Y N$ accumulation not only activated PDI but resulted in the accumulation of a reduced form of PDI due to an increasingly reduced ER redox environment (Figure 3).

\section{REFERENCES}

Agarraberes, F. A., Terlecky, S. R., and Dice, J. F. (1997). An intralysosomal hsp70 is required for a selective pathway of lysosomal protein degradation. J. Cell Biol. 137, 825-834. doi: $10.1083 /$ jcb.137.4.825
Protein disulfide isomerase inhibitors bacitracin and cystamine prevented the accumulation of $\alpha$-SYN and MPP+induced reductive shift in the ER by hindering PDI excessive reduction (Lehtonen et al., 2016). Moreover, the data suggest that redox misbalance and hydrogen peroxide production due to PDI re-oxidation in the ER are the outcome of a severe toxic insult caused by $\alpha-S Y N$ accumulation. Calpain is a $\mathrm{Ca}^{2+}$-sensitive non-lysosomal protease reported to be disruptive in $\mathrm{SN}$ of $\mathrm{PD}$ patients as well as in experimental PD models (Crocker et al., 2003). In the model described by Lehtonen et al. (2016), the release of $\mathrm{Ca}^{2+}$ was succesfully blocked not only by 2-aminoethoxydiphenyl borate (2$\mathrm{APB}$ ), an inositiol-3-phosphate receptor (IP3R) inhibitor, but also by bacitracin, a PDI inhibitor, and it promoted neuroblastoma cell survival. Additionally, ALLN (N-acetylleu-leu-norleual, $\quad N$-acetyl-L-leucyl-L-leucyl-L-norleucinal), a calpain I inhibitor, protected these cells from MPP+ toxicity. Overall, these results are in line with a previously published study using a PC12 cell model of Huntington's disease showing the potential of PDI inhibitors to suppress the cells' death induced by misfolded proteins (Hoffstrom et al., 2010). Importantly, a beneficial effect of PDI inhibition is coupled with consecutive enhancement of autophagy that is turned on to support cell survival. Furthermore, PDI inhibition also protected against $\mathrm{MPP}+$-induced DA neurodegeneration in Caenorhabditis elegans.

Collectivelly, excessive protein refolding taking place in the ER leads to an increase in the reduced form of PDI and to the activation of the PDI-Ero1 cycle, causing overproduction of hydrogen peroxide and promoting generation of ROS. These events lead to the dysregulation of IP3R that causes an increase in cytosolic calcium followed by calpain activationinduced apoptosis. In contrast, PDI inhibition prevents ER redox imbalance and enhances the autophagic clearance pathway. Therefore, when considering therapeutic approaches, it is necessary to take into account the balance between ER-linked refolding or/and alternative protein clearance by autophagy.

\section{AUTHOR CONTRIBUTIONS}

All authors listed have made a substantial, direct and intellectual contribution to the work, and approved it for publication.

\section{FUNDING}

This study was supported by Academy of Finland, University of Eastern Finland, University of Helsinki and the Finnish Parkinson Foundation.

Ahmed, I., Liang, Y., Schools, S., Dawson, V. L., Dawson, T. M., and Savitt, J. M. (2012). Development and characterization of a new Parkinson's disease model resulting from impaired autophagy. J. Neurosci. Off. J. Soc. Neurosci. 32, 16503-16509. doi: 10.1523/JNEUROSCI.0209-12. 2012 
Alvarez-Erviti, L., Rodriguez-Oroz, M. C., Cooper, J. M., Caballero, C., Ferrer, I., Obeso, J. A., et al. (2010). Chaperone-mediated autophagy markers in Parkinson disease brains. Arch. Neurol. 67, 1464-1472. doi: 10.1001/archneurol. 2010.198

Alvarez-Erviti, L., Seow, Y., Schapira, A. H. V., Rodriguez-Oroz, M. C., Obeso, J. A., and Cooper, J. M. (2013). Influence of microRNA deregulation on chaperonemediated autophagy and $\alpha$-synuclein pathology in Parkinson's disease. Cell Death Dis. 4:e545. doi: 10.1038/cddis.2013.73

Ambrosi, G., Ghezzi, C., Zangaglia, R., Levandis, G., Pacchetti, C., and Blandini, F. (2015). Ambroxol-induced rescue of defective glucocerebrosidase is associated with increased LIMP-2 and saposin C levels in GBA1 mutant Parkinson's disease cells. Neurobiol. Dis. 82, 235-242. doi: 10.1016/j.nbd.2015. 06.008

Anglade, P., Vyas, S., Javoy-Agid, F., Herrero, M. T., Michel, P. P., Marquez, J., et al. (1997). Apoptosis and autophagy in nigral neurons of patients with Parkinson's disease. Histol. Histopathol. 12, 25-31.

Anguiano, J., Garner, T. P., Mahalingam, M., Das, B. C., Gavathiotis, E., and Cuervo, A. M. (2013). Chemical modulation of chaperone-mediated autophagy by retinoic acid derivatives. Nat. Chem. Biol. 9, 374-382. doi: 10.1038/ nchembio. 1230

Arai, K., Kato, N., Kashiwado, K., and Hattori, T. (2000). Pure autonomic failure in association with human alpha-synucleinopathy. Neurosci. Lett. 296, 171-173. doi: 10.1016/s0304-3940(00)01623-2

Bai, X., Wey, M. C.-Y., Fernandez, E., Hart, M. J., Gelfond, J., Bokov, A. F., et al. (2015). Rapamycin improves motor function, reduces 4-hydroxynonenal adducted protein in brain, and attenuates synaptic injury in a mouse model of synucleinopathy. Pathobiol. Aging Age Relat. Dis. 5:28743. doi: 10.3402/pba.v5. 28743

Baltazar, G. C., Guha, S., Lu, W., Lim, J., Boesze-Battaglia, K., Laties, A. M., et al. (2012). Acidic nanoparticles are trafficked to lysosomes and restore an acidic lysosomal $\mathrm{pH}$ and degradative function to compromised ARPE-19 cells. PLoS One 7:e49635. doi: 10.1371/journal.pone.0049635

Bartels, T., Choi, J. G., and Selkoe, D. J. (2011). $\alpha$-Synuclein occurs physiologically as a helically folded tetramer that resists aggregation. Nature 477, 107-110. doi: 10.1038 /nature10324

Bellucci, A., Navarria, L., Zaltieri, M., Falarti, E., Bodei, S., Sigala, S., et al. (2011). Induction of the unfolded protein response by $\alpha$-synuclein in experimental models of Parkinson's disease. J. Neurochem. 116, 588-605. doi: 10.1111/j.14714159.2010.07143.x

Bentea, E., Verbruggen, L., and Massie, A. (2017). The proteasome inhibition model of Parkinson's disease. J. Park. Dis. 7, 31-63. doi: 10.1016/j.bcp.2012. 05.019

Bento, C. F., Renna, M., Ghislat, G., Puri, C., Ashkenazi, A., Vicinanza, M., et al. (2016). Mammalian autophagy: how does it work? Annu. Rev. Biochem. 85, 685-713. doi: 10.1146/annurev-biochem-060815-014556

Berthet, A., Bezard, E., Porras, G., Fasano, S., Barroso-Chinea, P., Dehay, B., et al. (2012). L-DOPA impairs proteasome activity in parkinsonism through D1 dopamine receptor. J. Neurosci. Off. J. Soc. Neurosci. 32, 681-691. doi: 10.1523/jneurosci.1541-11.2012

Bertolotti, A., Zhang, Y., Hendershot, L. M., Harding, H. P., and Ron, D. (2000). Dynamic interaction of $\mathrm{BiP}$ and ER stress transducers in the unfolded-protein response. Nat. Cell Biol. 2, 326-332. doi: 10.1038/35014014

Bertoncini, C. W., Jung, Y.-S., Fernandez, C. O., Hoyer, W., Griesinger, C., Jovin, T. M., et al. (2005). Release of long-range tertiary interactions potentiates aggregation of natively unstructured alpha-synuclein. Proc. Natl. Acad. Sci. U.S.A. 102, 1430-1435. doi: 10.1073/pnas.0407146102

Betarbet, R., Canet-Aviles, R. M., Sherer, T. B., Mastroberardino, P. G., McLendon, C., Kim, J.-H., et al. (2006). Intersecting pathways to neurodegeneration in Parkinson's disease: effects of the pesticide rotenone on DJ-1, alpha-synuclein, and the ubiquitin-proteasome system. Neurobiol. Dis. 22, 404-420. doi: 10. 1016/j.nbd.2005.12.003

Beyer, K., Domingo-Sàbat, M., and Ariza, A. (2009). Molecular pathology of lewy body diseases. Int. J. Mol. Sci. 10, 724-745. doi: 10.3390/ijms10030724

Binolfi, A., Theillet, F.-X., and Selenko, P. (2012). Bacterial in-cell NMR of human $\alpha$-synuclein: a disordered monomer by nature? Biochem. Soc. Trans. 40, 950954. doi: 10.1042/bst20120096

Blandini, F., Sinforiani, E., Pacchetti, C., Samuele, A., Bazzini, E., Zangaglia, R., et al. (2006). Peripheral proteasome and caspase activity in Parkinson disease and Alzheimer disease. Neurology 66, 529-534. doi: 10.1212/01.wnl. 0000198511.09968.b3

Blanz, J., and Saftig, P. (2016). Parkinson's disease: acid-glucocerebrosidase activity and alpha-synuclein clearance. J. Neurochem. 139(Suppl. 1), 198-215. doi: 10. $1111 /$ jnc. 13517

Bourdenx, M., Daniel, J., Genin, E., Soria, F. N., Blanchard-Desce, M., Bezard, E., et al. (2016). Nanoparticles restore lysosomal acidification defects: implications for Parkinson and other lysosomal-related diseases. Autophagy 12, 472-483. doi: 10.1080/15548627.2015.1136769

Bové, J., Martínez-Vicente, M., and Vila, M. (2011). Fighting neurodegeneration with rapamycin: mechanistic insights. Nat. Rev. Neurosci. 12, 437-452. doi: $10.1038 /$ nrn3068

Bukhatwa, S., Zeng, B.-Y., Rose, S., and Jenner, P. (2010). A comparison of changes in proteasomal subunit expression in the substantia nigra in Parkinson's disease, multiple system atrophy and progressive supranuclear palsy. Brain Res. 1326, 174-183. doi: 10.1016/j.brainres.2010.02.045

Burchell, V. S., Nelson, D. E., Sanchez-Martinez, A., Delgado-Camprubi, M., Ivatt, R. M., Pogson, J. H., et al. (2013). The Parkinson's disease-linked proteins Fbxo7 and Parkin interact to mediate mitophagy. Nat. Neurosci. 16, 1257-1265. doi: $10.1038 / \mathrm{nn} .3489$

Burré, J., Sharma, M., Tsetsenis, T., Buchman, V., Etherton, M. R., and Südhof, T. C. (2010). Alpha-synuclein promotes SNARE-complex assembly in vivo and in vitro. Science 329, 1663-1667. doi: 10.1126/science.1195227

Calfon, M., Zeng, H., Urano, F., Till, J. H., Hubbard, S. R., Harding, H. P., et al. (2002). IRE1 couples endoplasmic reticulum load to secretory capacity by processing the XBP-1 mRNA. Nature 415, 92-96. doi: 10.1038/415092a

Caneda-Ferrón, B., De Girolamo, L. A., Costa, T., Beck, K. E., Layfield, R., and Billett, E. E. (2008). Assessment of the direct and indirect effects of $\mathrm{MPP}+$ and dopamine on the human proteasome: implications for Parkinson's disease aetiology. J. Neurochem. 105, 225-238. doi: 10.1111/j.1471-4159.2007. 05130.x

Casarejos, M. J., Solano, R. M., Gómez, A., Perucho, J., de Yébenes, J. G., and Mena, M. A. (2011). The accumulation of neurotoxic proteins, induced by proteasome inhibition, is reverted by trehalose, an enhancer of autophagy, in human neuroblastoma cells. Neurochem. Int. 58, 512-520. doi: 10.1016/j.neuint. 2011.01 .008

Celardo, I., Costa, A. C., Lehmann, S., Jones, C., Wood, N., Mencacci, N. E., et al. (2016). Mitofusin-mediated ER stress triggers neurodegeneration in pink1/parkin models of Parkinson's disease. Cell Death Dis. 7:e2271. doi: 10. 1038/cddis.2016.173

Chen, L., Jin, J., Davis, J., Zhou, Y., Wang, Y., Liu, J., et al. (2007). Oligomeric alphasynuclein inhibits tubulin polymerization. Biochem. Biophys. Res. Commun. 356, 548-553. doi: 10.1016/j.bbrc.2007.02.163

Chen, L., Xie, Z., Turkson, S., and Zhuang, X. (2015). A53T human $\alpha$-synuclein overexpression in transgenic mice induces pervasive mitochondria macroautophagy defects preceding dopamine neuron degeneration. J. Neurosci. Off. J. Soc. Neurosci. 35, 890-905. doi: 10.1523/JNEUROSCI.0089-14.2015

Chen, Q., Thorpe, J., and Keller, J. N. (2005). Alpha-synuclein alters proteasome function, protein synthesis, and stationary phase viability. J. Biol. Chem. 280, 30009-30017. doi: 10.1074/jbc.m501308200

Chiasserini, D., Paciotti, S., Eusebi, P., Persichetti, E., Tasegian, A., KurzawaAkanbi, M., et al. (2015). Selective loss of glucocerebrosidase activity in sporadic Parkinson's disease and dementia with Lewy bodies. Mol. Neurodegener. 10:15.

Choi, B.-K., Choi, M.-G., Kim, J.-Y., Yang, Y., Lai, Y., Kweon, D.-H., et al. (2013). Large $\alpha$-synuclein oligomers inhibit neuronal SNARE-mediated vesicle docking. Proc. Natl. Acad. Sci. U.S.A. 110, 4087-4092. doi: 10.1073/pnas. 1218424110

Chou, A. P., Li, S., Fitzmaurice, A. G., and Bronstein, J. M. (2010). Mechanisms of rotenone-induced proteasome inhibition. Neurotoxicology 31, 367-372. doi: 10.1016/j.neuro.2010.04.006

Choubey, V., Safiulina, D., Vaarmann, A., Cagalinec, M., Wareski, P., Kuum, M., et al. (2011). Mutant A53T alpha-synuclein induces neuronal death by increasing mitochondrial autophagy. J. Biol. Chem. 286, 10814-10824. doi: 10.1074/jbc.M110.132514

Chu, Y., Dodiya, H., Aebischer, P., Olanow, C. W., and Kordower, J. H. (2009). Alterations in lysosomal and proteasomal markers in Parkinson's disease: relationship to alpha-synuclein inclusions. Neurobiol. Dis. 35, 385-398. doi: 10.1016/j.nbd.2009.05.023 
Chung, C. Y., Khurana, V., Auluck, P. K., Tardiff, D. F., Mazzulli, J. R., Soldner, F., et al. (2013). Identification and rescue of $\alpha$-synuclein toxicity in parkinson patient-derived neurons. Science 342, 983-987. doi: 10.1126/science.1245296

Colla, E., Jensen, P. H., Pletnikova, O., Troncoso, J. C., Glabe, C., and Lee, M. K. (2012). Accumulation of toxic $\alpha$-synuclein oligomer within endoplasmic reticulum occurs in $\alpha$-synucleinopathy in vivo. J. Neurosci. Off. J. Soc. Neurosci. 32, 3301-3305. doi: 10.1523/JNEUROSCI.5368-11.2012

Conn, K. J., Gao, W., McKee, A., Lan, M. S., Ullman, M. D., Eisenhauer, P. B., et al. (2004). Identification of the protein disulfide isomerase family member PDIp in experimental Parkinson's disease and Lewy body pathology. Brain Res. 1022, 164-172. doi: 10.1016/j.brainres.2004.07.026

Coune, P. G., Schneider, B. L., and Aebischer, P. (2012). Parkinson's disease: gene therapies. Cold Spring Harb. Perspect. Med. 2:a009431. doi: 10.1101/cshperspect. a009431

Crabtree, D., Dodson, M., Ouyang, X., Boyer-Guittaut, M., Liang, Q., Ballestas, M. E., et al. (2014). Over-expression of an inactive mutant cathepsin D increases endogenous alpha-synuclein and cathepsin B activity in SH-SY5Y cells. J. Neurochem. 128, 950-961. doi: 10.1111/jnc.12497

Credle, J. J., Forcelli, P. A., Delannoy, M., Oaks, A. W., Permaul, E., Berry, D. L., et al. (2015). $\alpha$-synuclein-mediated inhibition of ATF6 processing into COPII vesicles disrupts UPR signaling in Parkinson's disease. Neurobiol. Dis. 76, 112-125. doi: 10.1016/j.nbd.2015.02.005

Crews, L., Spencer, B., Desplats, P., Patrick, C., Paulino, A., Rockenstein, E., et al. (2010). Selective molecular alterations in the autophagy pathway in patients with Lewy body disease and in models of alpha-synucleinopathy. PLoS One 5:e9313. doi: 10.1371/journal.pone.0009313

Crocker, S. J., Smith, P. D., Jackson-Lewis, V., Lamba, W. R., Hayley, S. P., Grimm, E., et al. (2003). Inhibition of calpains prevents neuronal and behavioral deficits in an MPTP mouse model of Parkinson's disease. J. Neurosci. Off. J. Soc. Neurosci. 23, 4081-4091. doi: 10.1523/jneurosci.23-10-04081.2003

Cuervo, A. M., and Dice, J. F. (1996). A receptor for the selective uptake and degradation of proteins by lysosomes. Science 273, 501-503. doi: 10.1126/ science.273.5274.501

Cuervo, A. M., Stefanis, L., Fredenburg, R., Lansbury, P. T., and Sulzer, D. (2004). Impaired degradation of mutant alpha-synuclein by chaperone-mediated autophagy. Science 305, 1292-1295. doi: 10.1126/science.1101738

Cullen, V., Lindfors, M., Ng, J., Paetau, A., Swinton, E., Kolodziej, P., et al. (2009). Cathepsin D expression level affects alpha-synuclein processing, aggregation, and toxicity in vivo. Mol. Brain 2:5. doi: 10.1186/1756-6606-2-5

Curry, D. W., Stutz, B., Andrews, Z. B., and Elsworth, J. D. (2018). Targeting AMPK signaling as a neuroprotective strategy in parkinson's disease. J. Park. Dis. 8, 161-181. doi: 10.3233/JPD-171296

DeBosch, B. J., Heitmeier, M. R., Mayer, A. L., Higgins, C. B., Crowley, J. R., Kraft, T. E., et al. (2016). Trehalose inhibits solute carrier 2A (SLC2A) proteins to induce autophagy and prevent hepatic steatosis. Sci. Signal. 9:ra21. doi: 10.1126/ scisignal.aac5472

Decressac, M., and Bjorklund, A. (2013). mTOR inhibition alleviates L-DOPAinduced dyskinesia in parkinsonian rats. J. Parkinsons Dis. 2013, 13-17. doi: 10.3233/JPD- 120155

Decressac, M., Mattsson, B., Weikop, P., Lundblad, M., Jakobsson, J., and Björklund, A. (2013). TFEB-mediated autophagy rescues midbrain dopamine neurons from $\alpha$-synuclein toxicity. Proc. Natl. Acad. Sci. U.S.A. 110, E1817E1826. doi: 10.1073/pnas.1305623110

Dehay, B., Bové, J., Rodríguez-Muela, N., Perier, C., Recasens, A., Boya, P., et al. (2010). Pathogenic lysosomal depletion in Parkinson's disease. J. Neurosci. Off. J. Soc. Neurosci. 30, 12535-12544. doi: 10.1523/jneurosci.1920-10.2010

Dehay, B., Ramirez, A., Martinez-Vicente, M., Perier, C., Canron, M.-H., Doudnikoff, E., et al. (2012). Loss of P-type ATPase ATP13A2/PARK9 function induces general lysosomal deficiency and leads to Parkinson disease neurodegeneration. Proc. Natl. Acad. Sci. U.S.A. 109, 9611-9616. doi: 10.1073/ pnas. 1112368109

Devine, M. J., Gwinn, K., Singleton, A., and Hardy, J. (2011). Parkinson's disease and $\alpha$-synuclein expression. Mov. Disord. Off. J. Mov. Disord. Soc. 26, 21602168. doi: $10.1083 /$ jcb.201003122

di Domenico, A., Carola, G., Calatayud, C., Pons-Espinal, M., Muñoz, J. P., Richaud-Patin, Y., et al. (2019). Patient-specific iPSC-derived astrocytes contribute to non-cell-autonomous neurodegeneration in Parkinson's disease. Stem Cell Rep. 12, 213-229. doi: 10.1016/j.stemcr.2018.12.011
Diao, J., Burré, J., Vivona, S., Cipriano, D. J., Sharma, M., Kyoung, M., et al. (2013). Native $\alpha$-synuclein induces clustering of synaptic-vesicle mimics via binding to phospholipids and synaptobrevin-2/VAMP2. ELife 2:e00592. doi: 10.7554/eLife.00592

Dice, J. F. (1990). Peptide sequences that target cytosolic proteins for lysosomal proteolysis. Trends Biochem. Sci. 15, 305-309. doi: 10.1016/0968-0004(90) 90019-8

Dijkstra, A. A., Ingrassia, A., de Menezes, R. X., van Kesteren, R. E., Rozemuller, A. J. M., Heutink, P., et al. (2015). Evidence for immune response, axonal dysfunction and reduced endocytosis in the substantia nigra in early stage Parkinson's disease. PLoS One 10:e0128651. doi: 10.1371/journal.pone.0128651

Dulovic, M., Jovanovic, M., Xilouri, M., Stefanis, L., Harhaji-Trajkovic, L., KravicStevovic, T., et al. (2014). The protective role of AMP-activated protein kinase in alpha-synuclein neurotoxicity in vitro. Neurobiol. Dis. 63, 1-11. doi: 10.1016/ j.nbd.2013.11.002

Egawa, N., Yamamoto, K., Inoue, H., Hikawa, R., Nishi, K., Mori, K., et al. (2011). The endoplasmic reticulum stress sensor, ATF $6 \alpha$, protects against neurotoxininduced dopaminergic neuronal death. J. Biol. Chem. 286, 7947-7957.

Elstner, M., Morris, C. M., Heim, K., Bender, A., Mehta, D., Jaros, E., et al. (2011). Expression analysis of dopaminergic neurons in Parkinson's disease and aging links transcriptional dysregulation of energy metabolism to cell death. Acta Neuropathol. (Berl.) 122, 75-86. doi: 10.1007/s00401-011-0828-9

Emmanouilidou, E., Stefanis, L., and Vekrellis, K. (2010). Cell-produced alphasynuclein oligomers are targeted to, and impair, the $26 \mathrm{~S}$ proteasome. Neurobiol. Aging 31, 953-968. doi: 10.1016/j.neurobiolaging.2008.07.008

Erustes, A. G., Stefani, F. Y., Terashima, J. Y., Stilhano, R. S., Monteforte, P. T., da Silva, et al. (2018). Overexpression of $\alpha$-synuclein in an astrocyte cell line promotes autophagy inhibition and apoptosis. J. Neurosci. Res. 96, 160-171. doi: 10.1002/jnr.24092

Eschbach, J., von Einem, B., Müller, K., Bayer, H., Scheffold, A., Morrison, B. E., et al. (2015). Mutual exacerbation of peroxisome proliferator-activated receptor $\gamma$ coactivator $1 \alpha$ deregulation and $\alpha$-synuclein oligomerization. Ann. Neurol. 77, 15-32. doi: 10.1002/ana.24294

Fanciulli, A., and Wenning, G. K. (2015). Multiple-system atrophy. N. Engl. J. Med. 372, 249-263.

Fares, M.-B., Ait-Bouziad, N., Dikiy, I., Mbefo, M. K., Jovièiæ, A., Kiely, A., et al. (2014). The novel Parkinson's disease linked mutation G51D attenuates in vitro aggregation and membrane binding of $\alpha$-synuclein, and enhances its secretion and nuclear localization in cells. Hum. Mol. Genet. 23, 4491-4509. doi: $10.1093 / \mathrm{hmg} / \mathrm{ddu} 165$

Fauvet, B., Mbefo, M. K., Fares, M.-B., Desobry, C., Michael, S., Ardah, M. T., et al. (2012). $\alpha$-Synuclein in central nervous system and from erythrocytes, mammalian cells, and Escherichia coli exists predominantly as disordered monomer. J. Biol. Chem. 287, 15345-15364. doi: 10.1074/jbc.M111.318949

Fels, D. R., and Koumenis, C. (2006). The PERK/eIF2alpha/ATF4 module of the UPR in hypoxia resistance and tumor growth. Cancer Biol. Ther. 5, 723-728. doi: $10.4161 /$ cbt.5.7.2967

Fornai, F., Schlüter, O. M., Lenzi, P., Gesi, M., Ruffoli, R., Ferrucci, M., et al. (2005). Parkinson-like syndrome induced by continuous MPTP infusion: convergent roles of the ubiquitin-proteasome system and alpha-synuclein. Proc. Natl. Acad. Sci. U.S.A. 102, 3413-3418. doi: 10.1073/pnas.0409713102

Friedman, L. G., Lachenmayer, M. L., Wang, J., He, L., Poulose, S. M., Komatsu, M., et al. (2012). Disrupted autophagy leads to dopaminergic axon and dendrite degeneration and promotes presynaptic accumulation of $\alpha$-synuclein and LRRK2 in the brain. J. Neurosci. Off. J. Soc. Neurosci. 32, 7585-7593. doi: 10.1523/JNEUROSCI.5809-11.2012

Furukawa, Y., Vigouroux, S., Wong, H., Guttman, M., Rajput, A. H., Ang, L., et al. (2002). Brain proteasomal function in sporadic Parkinson's disease and related disorders. Ann. Neurol. 51, 779-782. doi: 10.1002/ana.10207

Gan-Or, Z., Dion, P. A., and Rouleau, G. A. (2015). Genetic perspective on the role of the autophagy-lysosome pathway in Parkinson disease. Autophagy 11, 1443-1457. doi: 10.1080/15548627.2015.1067364

Gegg, M. E., Burke, D., Heales, S. J. R., Cooper, J. M., Hardy, J., Wood, N. W., et al. (2012). Glucocerebrosidase deficiency in substantia nigra of parkinson disease brains. Ann. Neurol. 72, 455-463. doi: 10.1002/ana.23614

Ghee, M., Fournier, A., and Mallet, J. (2000). Rat alpha-synuclein interacts with Tat binding protein 1 , a component of the $26 \mathrm{~S}$ proteasomal complex. J. Neurochem. 75, 2221-2224. doi: 10.1046/j.1471-4159.2000.0752221.x 
Glickman, M. H., and Ciechanover, A. (2002). The ubiquitin-proteasome proteolytic pathway: destruction for the sake of construction. Physiol. Rev. 82, 373-428. doi: 10.1152/physrev.00027.2001

Gonçalves, S., and Outeiro, T. F. (2013). Assessing the subcellular dynamics of alpha-synuclein using photoactivation microscopy. Mol. Neurobiol. 47, 10811092. doi: 10.1007/s12035-013-8406-x

Gorbatyuk, M. S., Shabashvili, A., Chen, W., Meyers, C., Sullivan, L. F., Salganik, M., et al. (2012). Glucose regulated protein 78 diminishes $\alpha$-synuclein neurotoxicity in a rat model of Parkinson disease. Mol. Ther. J. Am. Soc. Gene Ther. 20, 1327-1337. doi: 10.1038/mt.2012.28

Gotoh, T., Oyadomari, S., Mori, K., and Mori, M. (2002). Nitric oxide-induced apoptosis in RAW 264.7 macrophages is mediated by endoplasmic reticulum stress pathway involving ATF6 and CHOP. J. Biol. Chem. 277, 12343-12350. doi: 10.1074/jbc.m107988200

Grünblatt, E., Mandel, S., Jacob-Hirsch, J., Zeligson, S., Amariglo, N., Rechavi, G., et al. (2004). Gene expression profiling of parkinsonian substantia nigra pars compacta; alterations in ubiquitin-proteasome, heat shock protein, iron and oxidative stress regulated proteins, cell adhesion/cellular matrix and vesicle trafficking genes. J. Neural Transm. Vienna Austria 1996, 1543-1573.

Gully, J. C., Sergeyev, V. G., Bhootada, Y., Mendez-Gomez, H., Meyers, C. A., Zolotukhin, S., et al. (2016). Up-regulation of activating transcription factor 4 induces severe loss of dopamine nigral neurons in a rat model of Parkinson's disease. Neurosci. Lett. 627, 36-41. doi: 10.1016/j.neulet.2016.05.039

Han, J., Back, S. H., Hur, J., Lin, Y.-H., Gildersleeve, R., Shan, J., et al. (2013). ERstress-induced transcriptional regulation increases protein synthesis leading to cell death. Nat. Cell Biol. 15, 481-490. doi: 10.1038/ncb2738

Harding, H. P., Novoa, I., Zhang, Y., Zeng, H., Wek, R., Schapira, M., et al. (2000). Regulated translation initiation controls stress-induced gene expression in mammalian cells. Mol. Cell 6, 1099-1108. doi: 10.1016/s1097-2765(00) 00108-8

Harding, H. P., Zhang, Y., and Ron, D. (1999). Protein translation and folding are coupled by an endoplasmic-reticulum-resident kinase. Nature 397, 271-274. doi: $10.1038 / 16729$

Haynes, C. M., Titus, E. A., and Cooper, A. A. (2004). Degradation of misfolded proteins prevents ER-derived oxidative stress and cell death. Mol. Cell 15, 767-776. doi: 10.1016/j.molcel.2004.08.025

Haze, K., Yoshida, H., Yanagi, H., Yura, T., and Mori, K. (1999). Mammalian transcription factor ATF6 is synthesized as a transmembrane protein and activated by proteolysis in response to endoplasmic reticulum stress. Mol. Biol. Cell 10, 3787-3799. doi: 10.1091/mbc.10.11.3787

He, C. H., Gong, P., Hu, B., Stewart, D., Choi, M. E., Choi, A. M., et al. (2001). Identification of activating transcription factor 4 (ATF4) as an Nrf2-interacting protein. Implication for heme oxygenase-1 gene regulation. J. Biol. Chem. 276, 20858-20865. doi: 10.1074/jbc.m101198200

He, Q., Koprich, J. B., Wang, Y., Yu, W., Xiao, B., Brotchie, J. M., et al. (2016). Treatment with trehalose prevents behavioral and neurochemical deficits produced in an AAV $\alpha$-Synuclein rat model of Parkinson's disease. Mol. Neurobiol. 53, 2258-2268. doi: 10.1007/s12035-015-9173-7

Heman-Ackah, S. M., Manzano, R., Hoozemans, J. J., Scheper, W., Flynn, R., Haerty, W., et al. (2017). Alpha-synuclein induces the unfolded protein response in Parkinson's disease SNCA triplication iPSC-derived neurons. Hum. Mol. Genet. 26, 4441-4450. doi: 10.1093/hmg/ddx331

Ho, D. H., Kim, H., Nam, D., Sim, H., Kim, J., Kim, H. G., et al. (2018). LRRK2 impairs autophagy by mediating phosphorylation of leucyl-tRNA synthetase. Cell Biochem. Funct. 36, 431-442. doi: 10.1002/cbf.3364

Hoffstrom, B. G., Kaplan, A., Letso, R., Schmid, R. S., Turmel, G. J., Lo, D. C., et al. (2010). Inhibitors of protein disulfide isomerase suppress apoptosis induced by misfolded proteins. Nat. Chem. Biol. 6, 900-906. doi: 10.1038/nchembio.467

Hou, L., Xiong, N., Liu, L., Huang, J., Han, C., Zhang, G., et al. (2015). Lithium protects dopaminergic cells from rotenone toxicity via autophagy enhancement. BMC Neurosci. 16:18. doi: 10.1186/s12868-015-0222-y

Huang, L., Xue, Y., Feng, D., Yang, R., Nie, T., Zhu, G., et al. (2017). Blockade of RyRs in the ER attenuates 6-OHDA-induced calcium overload, cellular hypoexcitability and apoptosis in dopaminergic neurons. Front. Cell. Neurosci. 11:52. doi: 10.3389/fncel.2017.00052

Huang, Z., Xu, Z., Wu, Y., and Zhou, Y. (2011). Determining nuclear localization of alpha-synuclein in mouse brains. Neuroscience 199, 318-332. doi: 10.1016/j. neuroscience.2011.10.016
Hwang, C., Sinskey, A. J., and Lodish, H. F. (1992). Oxidized redox state of glutathione in the endoplasmic reticulum. Science 257, 1496-1502. doi: 10. 1126/science. 1523409

Issa, A.-R., Sun, J., Petitgas, C., Mesquita, A., Dulac, A., Robin, M., et al. (2018). The lysosomal membrane protein LAMP2A promotes autophagic flux and prevents SNCA-induced Parkinson disease-like symptoms in the Drosophila brain. Autophagy 14, 1898-1910. doi: 10.1080/15548627.2018.1491489

Janezic, S., Threlfell, S., Dodson, P. D., Dowie, M. J., Taylor, T. N., Potgieter, D., et al. (2013). Deficits in dopaminergic transmission precede neuron loss and dysfunction in a new Parkinson model. Proc. Natl. Acad. Sci. U.S.A. 110, E4016-E4025. doi: 10.1073/pnas.1309143110

Kalia, L. V., and Kalia, S. K. (2015). $\alpha$-Synuclein and lewy pathology in Parkinson's disease. Curr. Opin. Neurol. 28, 375-381.

Kalia, L. V., and Lang, A. E. (2015). Parkinson's disease. Lancet Lond. Engl. 386, 896-912.

Katila, N., Bhurtel, S., Shadfar, S., Srivastav, S., Neupane, S., Ojha, U., et al. (2017). Metformin lowers $\alpha$-synuclein phosphorylation and upregulates neurotrophic factor in the MPTP mouse model of Parkinson's disease. Neuropharmacology 125, 396-407. doi: 10.1016/j.neuropharm.2017.08.015

Khanna, R., Benjamin, E. R., Pellegrino, L., Schilling, A., Rigat, B. A., Soska, R., et al. (2010). The pharmacological chaperone isofagomine increases the activity of the Gaucher disease L444P mutant form of beta-glucosidase. FEBS J. 277, 1618-1638. doi: 10.1111/j.1742-4658.2010.07588.x

Kilpatrick, K., Zeng, Y., Hancock, T., and Segatori, L. (2015). Genetic and chemical activation of TFEB mediates clearance of aggregated $\alpha$-synuclein. PLoS One 10:e0120819. doi: 10.1371/journal.pone.0120819

Klein, C., and Westenberger, A. (2012). Genetics of Parkinson's disease. Cold Spring Harb. Perspect. Med. 2:a008888. doi: 10.1101/cshperspect.a008888

Klucken, J., Poehler, A.-M., Ebrahimi-Fakhari, D., Schneider, J., Nuber, S., Rockenstein, E., et al. (2012). Alpha-synuclein aggregation involves a bafilomycin A 1-sensitive autophagy pathway. Autophagy 8, 754-766. doi: 10. 4161/auto. 19371

Koch, J. C., Bitow, F., Haack, J., d'Hedouville, Z., Zhang, J.-N., Tönges, L., et al. (2015). Alpha-Synuclein affects neurite morphology, autophagy, vesicle transport and axonal degeneration in CNS neurons. Cell Death Dis. 6:e1811. doi: $10.1038 /$ cddis.2015.169

Kontopoulos, E., Parvin, J. D., and Feany, M. B. (2006). Alpha-synuclein acts in the nucleus to inhibit histone acetylation and promote neurotoxicity. Hum. Mol. Genet. 15, 3012-3023. doi: 10.1093/hmg/ddl243

Lan, D.-M., Liu, F.-T., Zhao, J., Chen, Y., Wu, J.-J., Ding, Z.-T., et al. (2012). Effect of trehalose on PC12 cells overexpressing wild-type or A53T mutant a-synuclein. Neurochem. Res. 37, 2025-2032. doi: 10.1007/s11064-012-0823-0

Lee, H.-J., Khoshaghideh, F., Lee, S., and Lee, S.-J. (2006). Impairment of microtubule-dependent trafficking by overexpression of alpha-synuclein. Eur. J. Neurosci. 24, 3153-3162. doi: 10.1111/j.1460-9568.2006.05210.x

Lee, H.-J., Khoshaghideh, F., Patel, S., and Lee, S.-J. (2004). Clearance of alphasynuclein oligomeric intermediates via the lysosomal degradation pathway. J. Neurosci. Off. J. Soc. Neurosci. 24, 1888-1896. doi: 10.1523/jneurosci.380903.2004

Lehtonen, Š, Jaronen, M., Vehviläinen, P., Lakso, M., Rudgalvyte, M., KeksaGoldsteine, V., et al. (2016). Inhibition of excessive oxidative protein folding is protective in MPP $(+)$ toxicity-induced Parkinson's disease models. Antioxid. Redox Signal. 25, 485-497. doi: 10.1089/ars.2015.6402

Li, G., Yang, H., Zhu, D., Huang, H., Liu, G., and Lun, P. (2014). Targeted suppression of chaperone-mediated autophagy by miR-320a promotes $\alpha$-synuclein aggregation. Int. J. Mol. Sci. 15, 15845-15857. doi: 10.3390/ ijms150915845

Lindersson, E., Beedholm, R., Højrup, P., Moos, T., Gai, W., Hendil, K. B., et al. (2004). Proteasomal inhibition by alpha-synuclein filaments and oligomers. J. Biol. Chem. 279, 12924-12934. doi: 10.1074/jbc.m306390200

Liu, C. Y., Wong, H. N., Schauerte, J. A., and Kaufman, R. J. (2002). The protein kinase/endoribonuclease IRE1alpha that signals the unfolded protein response has a luminal N-terminal ligand-independent dimerization domain. J. Biol. Chem. 277, 18346-18356. doi: 10.1074/jbc.m112454200

Liu, G., Aliaga, L., and Cai, H. (2012). $\alpha$-synuclein, LRRK2 and their interplay in Parkinson's disease. Future Neurol. 7, 145-153. doi: 10.2217/fnl.12.2

Lu, J.-H., Tan, J.-Q., Durairajan, S. S. K., Liu, L.-F., Zhang, Z.-H., Ma, L., et al. (2012). Isorhynchophylline, a natural alkaloid, promotes the degradation of 
alpha-synuclein in neuronal cells via inducing autophagy. Autophagy 8, 98-108. doi: 10.4161/auto.8.1.18313

Lundblad, M., Decressac, M., Mattsson, B., and Björklund, A. (2012). Impaired neurotransmission caused by overexpression of $\alpha$-Synuclein in nigral dopamine neurons. Proc. Natl. Acad. Sci. U.S.A. 109, 3213-3219. doi: 10.1073/pnas. 1200575109

Luo, J., Sun, L., Lin, X., Liu, G., Yu, J., Parisiadou, L., et al. (2014). A calcineurinand NFAT-dependent pathway is involved in $\alpha$-synuclein-induced degeneration of midbrain dopaminergic neurons. Hum. Mol. Genet. 23, 6567-6574. doi: $10.1093 / \mathrm{hmg} / \mathrm{ddu} 377$

Magalhaes, J., Gegg, M. E., Migdalska-Richards, A., and Schapira, A. H. (2018). Effects of ambroxol on the autophagy-lysosome pathway and mitochondria in primary cortical neurons. Sci. Rep. 8:1385. doi: 10.1038/s41598-018-19479-8

Mak, S. K., McCormack, A. L., Manning-Bog, A. B., Cuervo, A. M., and Di Monte, D. A. (2010). Lysosomal degradation of alpha-synuclein in vivo. J. Biol. Chem. 285, 13621-13629. doi: 10.1074/jbc.M109.074617

Malagelada, C., Jin, Z. H., Jackson-Lewis, V., Przedborski, S., and Greene, L. A. (2010). Rapamycin protects against neuron death in in vitro and in vivo models of Parkinson's disease. J. Neurosci. Off. J. Soc. Neurosci. 30, 1166-1175. doi: 10.1523/JNEUROSCI.3944-09.2010

Malek, N., Swallow, D., Grosset, K. A., Anichtchik, O., Spillantini, M., and Grosset, D. G. (2014). Alpha-synuclein in peripheral tissues and body fluids as a biomarker for Parkinson's disease - A systematic review. Acta Neurol. Scand. 130, 59-72. doi: 10.1111/ane.12247

Malkus, K. A., and Ischiropoulos, H. (2012). Regional deficiencies in chaperonemediated autophagy underlie $\alpha$-synuclein aggregation and neurodegeneration. Neurobiol. Dis. 46, 732-744. doi: 10.1016/j.nbd.2012.03.017

Martin, L. J., Pan, Y., Price, A. C., Sterling, W., Copeland, N. G., Jenkins, N. A., et al. (2006). Parkinson's disease alpha-synuclein transgenic mice develop neuronal mitochondrial degeneration and cell death. J. Neurosci. Off. J. Soc. Neurosci. 26, 41-50. doi: 10.1523/jneurosci.4308-05.2006

Martìn-Clemente, B., Alvarez-Castelao, B., Mayo, I., Sierra, A. B., Dìaz, V., Milán, M., et al. (2004). alpha-Synuclein expression levels do not significantly affect proteasome function and expression in mice and stably transfected PC12 cell lines. J. Biol. Chem. 279, 52984-52990. doi: 10.1074/jbc.m409028200

Martínez, J. H., Fuentes, F., Vanasco, V., Alvarez, S., Alaimo, A., Cassina, A., et al. (2018). Alpha-synuclein mitochondrial interaction leads to irreversible translocation and complex I impairment. Arch. Biochem. Biophys. 651, 1-12. doi: 10.1016/j.abb.2018.04.018

Martinez-Vicente, M., Talloczy, Z., Kaushik, S., Massey, A. C., Mazzulli, J., Mosharov, E. V., et al. (2008). Dopamine-modified alpha-synuclein blocks chaperone-mediated autophagy. J. Clin. Invest. 118, 777-788. doi: 10.1172/ JCI32806

Masliah, E., Rockenstein, E., Veinbergs, I., Mallory, M., Hashimoto, M., Takeda, A., et al. (2000). Dopaminergic loss and inclusion body formation in alphasynuclein mice: implications for neurodegenerative disorders. Science 287, 1265-1269. doi: 10.1126/science.287.5456.1265

McLean, P. J., Kawamata, H., and Hyman, B. T. (2001). Alpha-synuclein-enhanced green fluorescent protein fusion proteins form proteasome sensitive inclusions in primary neurons. Neuroscience 104, 901-912. doi: 10.1016/s0306-4522(01) 00113-0

McNaught, K. S. P., Belizaire, R., Isacson, O., Jenner, P., and Olanow, C. W. (2003). Altered proteasomal function in sporadic Parkinson's disease. Exp. Neurol. 179, 38-46. doi: 10.1006/exnr.2002.8050

McNaught, K. S. P., Belizaire, R., Jenner, P., Olanow, C. W., and Isacson, O. (2002a). Selective loss of $20 \mathrm{~S}$ proteasome alpha-subunits in the substantia nigra pars compacta in Parkinson's disease. Neurosci. Lett. 326, 155-158. doi: 10.1016/ s0304-3940(02)00296-3

McNaught, K. S. P., Mytilineou, C., Jnobaptiste, R., Yabut, J., Shashidharan, P., Jennert, P., et al. (2002b). Impairment of the ubiquitin-proteasome system causes dopaminergic cell death and inclusion body formation in ventral mesencephalic cultures. J. Neurochem. 81, 301-306. doi: 10.1046/j.1471-4159. 2002.00821.x

McNaught, K. S. P., Perl, D. P., Brownell, A.-L., and Olanow, C. W. (2004). Systemic exposure to proteasome inhibitors causes a progressive model of Parkinson's disease. Ann. Neurol. 56, 149-162. doi: 10.1002/ana.20186

McNeill, A., Magalhaes, J., Shen, C., Chau, K.-Y., Hughes, D., Mehta, A., et al. (2014). Ambroxol improves lysosomal biochemistry in glucocerebrosidase mutation-linked Parkinson disease cells. Brain J. Neurol. 137, 1481-1495. doi: 10.1093/brain/awu020

Melachroinou, K., Xilouri, M., Emmanouilidou, E., Masgrau, R., Papazafiri, P., Stefanis, L., et al. (2013). Deregulation of calcium homeostasis mediates secreted $\alpha$-synuclein-induced neurotoxicity. Neurobiol. Aging 34, 2853-2865. doi: 10. 1016/j.neurobiolaging.2013.06.006

Mercado, G., Valdés, P., and Hetz, C. (2013). An ERcentric view of Parkinson's disease. Trends Mol. Med. 19, 165-175. doi: 10.1016/j.molmed.2012.12.005

Meredith, G. E., and Rademacher, D. J. (2011). MPTP mouse models of Parkinson's disease: an update. J. Parkinsons Dis. 1, 19-33.

Migdalska-Richards, A., Daly, L., Bezard, E., and Schapira, A. H. V. (2016). Ambroxol effects in glucocerebrosidase and $\alpha$-synuclein transgenic mice. Ann. Neurol. 80, 766-775. doi: 10.1002/ana.24790

Migdalska-Richards, A., Ko, W. K. D., Li, Q., Bezard, E., and Schapira, A. H. V. (2017a). Oral ambroxol increases brain glucocerebrosidase activity in a nonhuman primate. Synapse 71:e21967. doi: 10.1002/syn.21967

Migdalska-Richards, A., Wegrzynowicz, M., Rusconi, R., Deangeli, G., Di Monte, D. A., Spillantini, M. G., et al. (2017b). The L444P Gbal mutation enhances alpha-synuclein induced loss of nigral dopaminergic neurons in mice. Brain J. Neurol. 140, 2706-2721. doi: 10.1093/brain/awx221

Miki, Y., Shimoyama, S., Kon, T., Ueno, T., Hayakari, R., Tanji, K., et al. (2018). Alteration of autophagy-related proteins in peripheral blood mononuclear cells of patients with Parkinson's disease. Neurobiol. Aging 63, 33-43. doi: 10.1016/j. neurobiolaging.2017.11.006

Miki, Y., Tanji, K., Mori, F., Utsumi, J., Sasaki, H., Kakita, A., et al. (2016). Alteration of upstream autophagy-related proteins (ULK1, ULK2, Beclin1, VPS34 and AMBRA1) in lewy body disease. Brain Pathol. Zurich Switz. 26, 359-370. doi: 10.1111/bpa.12297

Mollereau, B., Manié, S., and Napoletano, F. (2014). Getting the better of ER stress. J. Cell Commun. Signal. 8, 311-321. doi: 10.1007/s12079-014-0251-9

Mollereau, B., Rzechorzek, N. M., Roussel, B. D., Sedru, M., Van den Brink, D. M., Bailly-Maitre, B., et al. (2016). Adaptive preconditioning in neurological diseases - Therapeutic insights from proteostatic perturbations. Brain Res. 1648, 603-616. doi: 10.1016/j.brainres.2016.02.033

Moors, T. E., Hoozemans, J. J. M., Ingrassia, A., Beccari, T., Parnetti, L., ChartierHarlin, M.-C., et al. (2017). Therapeutic potential of autophagy-enhancing agents in Parkinson's disease. Mol. Neurodegener. 12:11.

Murphy, K. E., Gysbers, A. M., Abbott, S. K., Spiro, A. S., Furuta, A., Cooper, A., et al. (2015). Lysosomal-associated membrane protein 2 isoforms are differentially affected in early Parkinson's disease. Mov. Disord. Off. J. Mov. Disord. Soc. 30, 1639-1647. doi: 10.1002/mds.26141

Murphy, K. E., Gysbers, A. M., Abbott, S. K., Tayebi, N., Kim, W. S., Sidransky, E., et al. (2014). Reduced glucocerebrosidase is associated with increased $\alpha$-synuclein in sporadic Parkinson's disease. Brain J. Neurol. 137, 834-848. doi: 10.1093/brain/awt367

Mutez, E., Nkiliza, A., Belarbi, K., de Broucker, A., Vanbesien-Mailliot, C., Bleuse, S., et al. (2014). Involvement of the immune system, endocytosis and EIF2 signaling in both genetically determined and sporadic forms of Parkinson's disease. Neurobiol. Dis. 63, 165-170. doi: 10.1016/j.nbd.2013. 11.007

Naidoo, N. (2009). Cellular stress/the unfolded protein response: relevance to sleep and sleep disorders. Sleep Med. Rev. 13, 195-204. doi: 10.1016/j.smrv.2009. 01.001

Narita, A., Shirai, K., Itamura, S., Matsuda, A., Ishihara, A., Matsushita, K., et al. (2016). Ambroxol chaperone therapy for neuronopathic Gaucher disease: a pilot study. Ann. Clin. Transl. Neurol. 3, 200-215. doi: 10.1002/ acn 3.292

Nash, Y., Schmukler, E., Trudler, D., Pinkas-Kramarski, R., and Frenkel, D. (2017). DJ-1 deficiency impairs autophagy and reduces alpha-synuclein phagocytosis by microglia. J. Neurochem. 143, 584-594. doi: 10.1111/jnc.14222

Nemani, V. M., Lu, W., Berge, V., Nakamura, K., Onoa, B., Lee, M. K., et al. (2010). Increased expression of alpha-synuclein reduces neurotransmitter release by inhibiting synaptic vesicle reclustering after endocytosis. Neuron $65,66-79$. doi: 10.1016/j.neuron.2009.12.023

Ng, O. T. W., Chen, L. W., Chan, Y. S., and Yung, K. K. L. (2013). Small interfering RNA specific for N-methyl-D-aspartate receptor $2 \mathrm{~B}$ offers neuroprotection to dopamine neurons through activation of MAP kinase. Neurosignals 21, 42-54. doi: $10.1159 / 000334720$ 
Orenstein, S. J., Kuo, S.-H., Tasset, I., Arias, E., Koga, H., Fernandez-Carasa, I., et al. (2013). Interplay of LRRK2 with chaperone-mediated autophagy. Nat. Neurosci. 16, 394-406. doi: 10.1038/nn.3350

Oueslati, A., Schneider, B. L., Aebischer, P., and Lashuel, H. A. (2013). Polo-like kinase 2 regulates selective autophagic $\alpha$-synuclein clearance and suppresses its toxicity in vivo. Proc. Natl. Acad. Sci. U.S.A. 110, E3945-E3954. doi: 10.1073/ pnas. 1309991110

Pan, T., Rawal, P., Wu, Y., Xie, W., Jankovic, J., and Le, W. (2009). Rapamycin protects against rotenone-induced apoptosis through autophagy induction. Neuroscience 164, 541-551. doi: 10.1016/j.neuroscience.2009.08.014

Parzych, K. R., and Klionsky, D. J. (2014). An overview of autophagy: morphology, mechanism, and regulation. Antioxid. Redox Signal. 20, 460-473. doi: 10.1089/ ars.2013.5371

Patil, S. P., Jain, P. D., Ghumatkar, P. J., Tambe, R., and Sathaye, S. (2014). Neuroprotective effect of metformin in MPTP-induced Parkinson's disease in mice. Neuroscience 277, 747-754. doi: 10.1016/j.neuroscience.2014.07.046

Peelaerts, W., Bousset, L., Van der Perren, A., Moskalyuk, A., Pulizzi, R., Giugliano, M., et al. (2015). $\alpha$-Synuclein strains cause distinct synucleinopathies after local and systemic administration. Nature 522, 340-344. doi: 10.1038/nature 14547

Pérez-Revuelta, B. I., Hettich, M. M., Ciociaro, A., Rotermund, C., Kahle, P. J., Krauss, S., et al. (2014). Metformin lowers Ser-129 phosphorylated $\alpha$-synuclein levels via mTOR-dependent protein phosphatase 2A activation. Cell Death Dis. 5:e1209. doi: 10.1038/cddis.2014.175

Petrucelli, L., O’Farrell, C., Lockhart, P. J., Baptista, M., Kehoe, K., Vink, L., et al. (2002). Parkin protects against the toxicity associated with mutant alpha-synuclein: proteasome dysfunction selectively affects catecholaminergic neurons. Neuron 36, 1007-1019. doi: 10.1016/s0896-6273(02)01125-x

Pickart, C. M. (2001). Mechanisms underlying ubiquitination. Annu. Rev. Biochem. 70, 503-533. doi: 10.1146/annurev.biochem.70.1.503

Pickrell, A. M., and Youle, R. J. (2015). The roles of PINK1, parkin and mitochondrial fidelity in Parkinson's disease. Neuron 85, 257-273. doi: 10.1016/ j.neuron.2014.12.007

Plowey, E. D., Cherra, S. J., Liu, Y.-J., and Chu, C. T. (2008). Role of autophagy in G2019S-LRRK2-associated neurite shortening in differentiated SH-SY5Y cells. J. Neurochem. 105, 1048-1056. doi: 10.1111/j.1471-4159.2008.05217.x

Prots, I., Grosch, J., Brazdis, R.-M., Simmnacher, K., Veber, V., Havlicek, S., et al. (2018). $\alpha$-Synuclein oligomers induce early axonal dysfunction in human iPSCbased models of synucleinopathies. Proc. Natl. Acad. Sci. U.S.A. 115, 7813-7818. doi: 10.1073/pnas.1713129115

Prots, I., Veber, V., Brey, S., Campioni, S., Buder, K., Riek, R., et al. (2013). $\alpha$-Synuclein oligomers impair neuronal microtubule-kinesin interplay. J. Biol. Chem. 288, 21742-21754. doi: 10.1074/jbc.M113.451815

Rao, R. V., and Bredesen, D. E. (2004). Misfolded proteins, endoplasmic reticulum stress and neurodegeneration. Curr. Opin. Cell Biol. 16, 653-662. doi: 10.1016/ j.ceb.2004.09.012

Redmann, M., Wani, W. Y., Volpicelli-Daley, L., Darley-Usmar, V., and Zhang, J. (2017). Trehalose does not improve neuronal survival on exposure to alphasynuclein pre-formed fibrils. Redox Biol. 11, 429-437. doi: 10.1016/j.redox.2016. 12.032

Richter, F., Fleming, S. M., Watson, M., Lemesre, V., Pellegrino, L., Ranes, B., et al. (2014). A GCase chaperone improves motor function in a mouse model of synucleinopathy. Neurother. J. Am. Soc. Exp. Neurother. 11, 840-856. doi: 10.1007/s13311-014-0294-x

Rideout, H. J., Larsen, K. E., Sulzer, D., and Stefanis, L. (2001). Proteasomal inhibition leads to formation of ubiquitin/alpha-synuclein-immunoreactive inclusions in PC12 cells. J. Neurochem. 78, 899-908. doi: 10.1046/j.1471-4159. 2001.00474.x

Rodríguez-Navarro, J. A., Rodríguez, L., Casarejos, M. J., Solano, R. M., Gómez, A., Perucho, J., et al. (2010). Trehalose ameliorates dopaminergic and tau pathology in parkin deleted/tau overexpressing mice through autophagy activation. Neurobiol. Dis. 39, 423-438. doi: 10.1016/j.nbd.2010.05.014

Ronzitti, G., Bucci, G., Emanuele, M., Leo, D., Sotnikova, T. D., Mus, L. V., et al. (2014). Exogenous $\alpha$-synuclein decreases raft partitioning of Cav2.2 channels inducing dopamine release. J. Neurosci. Off. J. Soc. Neurosci. 34, 10603-10615. doi: 10.1523/JNEUROSCI.0608-14.2014

Rousseaux, M. W., de Haro, M., Lasagna-Reeves, C. A., De Maio, A., Park, J., JafarNejad, P., et al. (2016). TRIM28 regulates the nuclear accumulation and toxicity of both alpha-synuclein and tau. ELife 5:e19809.
Ryan, S. D., Dolatabadi, N., Chan, S. F., Zhang, X., Akhtar, M. W., Parker, J., et al. (2013). Isogenic human iPSC Parkinson's model shows nitrosative stressinduced dysfunction in MEF2-PGC1 $\alpha$ transcription. Cell 155, 1351-1364. doi: 10.1016/j.cell.2013.11.009

Sado, M., Yamasaki, Y., Iwanaga, T., Onaka, Y., Ibuki, T., Nishihara, S., et al. (2009). Protective effect against Parkinson's disease-related insults through the activation of XBP1. Brain Res. 1257, 16-24. doi: 10.1016/j.brainres.2008. 11.104

Salganik, M., Sergeyev, V. G., Shinde, V., Meyers, C. A., Gorbatyuk, M. S., Lin, J. H., et al. (2015). The loss of glucose-regulated protein 78 (GRP78) during normal aging or from siRNA knockdown augments human alpha-synuclein ( $\alpha$-syn) toxicity to rat nigral neurons. Neurobiol. Aging 36, 2213-2223. doi: 10.1016/j.neurobiolaging.2015.02.018

Sanchez-Martinez, A., Beavan, M., Gegg, M. E., Chau, K.-Y., Whitworth, A. J., and Schapira, A. H. V. (2016). Parkinson disease-linked GBA mutation effects reversed by molecular chaperones in human cell and fly models. Sci. Rep. 6:31380. doi: $10.1038 /$ srep31380

Santini, E., Heiman, M., Greengard, P., Valjent, E., and Fisone, G. (2009). Inhibition of mTOR signaling in Parkinson's disease prevents L-DOPA-induced dyskinesia. Sci. Signal. 2:ra36. doi: 10.1126/scisignal.2000308

Sarkar, S., Chigurupati, S., Raymick, J., Mann, D., Bowyer, J. F., Schmitt, T., et al. (2014). Neuroprotective effect of the chemical chaperone, trehalose in a chronic MPTP-induced Parkinson's disease mouse model. Neurotoxicology 44, 250-262. doi: 10.1016/j.neuro.2014.07.006

Sarkar, S., Davies, J. E., Huang, Z., Tunnacliffe, A., and Rubinsztein, D. C. (2007). Trehalose, a novel mTOR-independent autophagy enhancer, accelerates the clearance of mutant huntingtin and alpha-synuclein. J. Biol. Chem. 282, 56415652. doi: 10.1074/jbc.m609532200

Savolainen, M. H., Richie, C. T., Harvey, B. K., Männistö, P. T., MaguireZeiss, K. A., and Myöhänen, T. T. (2014). The beneficial effect of a prolyl oligopeptidase inhibitor, KYP-2047, on alpha-synuclein clearance and autophagy in A30P transgenic mouse. Neurobiol. Dis. 68, 1-15. doi: 10.1016/ j.nbd.2014.04.003

Schell, H., Hasegawa, T., Neumann, M., and Kahle, P. J. (2009). Nuclear and neuritic distribution of serine-129 phosphorylated alpha-synuclein in transgenic mice. Neuroscience 160, 796-804. doi: 10.1016/j.neuroscience.2009. 03.002

Schröder, M., and Kaufman, R. J. (2005). The mammalian unfolded protein response. Annu. Rev. Biochem. 74, 739-789.

Scott, D., and Roy, S. (2012). $\alpha$-Synuclein inhibits intersynaptic vesicle mobility and maintains recycling-pool homeostasis. J. Neurosci. Off. J. Soc. Neurosci. 32, 10129-10135. doi: 10.1523/JNEUROSCI.0535-12.2012

Settembre, C., Di Malta, C., Polito, V. A., Garcia Arencibia, M., Vetrini, F., Erdin, S., et al. (2011). TFEB links autophagy to lysosomal biogenesis. Science 332, 1429-1433. doi: 10.1126/science. 1204592

Shahpasandzadeh, H., Popova, B., Kleinknecht, A., Fraser, P. E., Outeiro, T. F., and Braus, G. H. (2014). Interplay between sumoylation and phosphorylation for protection against $\alpha$-synuclein inclusions. J. Biol. Chem. 289, 31224-31240. doi: 10.1074/jbc.M114.559237

Shaltouki, A., Hsieh, C.-H., Kim, M. J., and Wang, X. (2018). Alpha-synuclein delays mitophagy and targeting Miro rescues neuron loss in Parkinson's models. Acta Neuropathol. (Berl.) 136, 607-620. doi: 10.1007/s00401-018-1873-4

Sharon, R., Bar-Joseph, I., Frosch, M. P., Walsh, D. M., Hamilton, J. A., and Selkoe, D. J. (2003). The formation of highly soluble oligomers of alpha-synuclein is regulated by fatty acids and enhanced in Parkinson's disease. Neuron 37, 583-595. doi: 10.1016/s0896-6273(03)00024-2

Sheng, Y.-L., Chen, X., Hou, X.-O., Yuan, X., Yuan, B.-S., Yuan, Y.-Q., et al. (2017). Urate promotes SNCA/ $\alpha$-synuclein clearance via regulating mTOR-dependent macroautophagy. Exp. Neurol. 297, 138-147. doi: 10.1016/j.expneurol.2017.08. 007

Si, L., Xu, T., Wang, F., Liu, Q., and Cui, M. (2012). X-box-binding protein 1modified neural stem cells for treatment of Parkinson's disease. Neural Regen. Res. 7, 736-740. doi: 10.3969/j.issn.1673-5374.2012.10.003

Silveira, C. R. A., MacKinley, J., Coleman, K., Li, Z., Finger, E., Bartha, R., et al. (2019). Ambroxol as a novel disease-modifying treatment for Parkinson's disease dementia: protocol for a single-centre, randomized, doubleblind, placebo-controlled trial. BMC Neurol. 19:20. doi: 10.1186/s12883-0191252-3 
Singleton, A. B., Farrer, M., Johnson, J., Singleton, A., Hague, S., Kachergus, J., et al. (2003). alpha-Synuclein locus triplication causes Parkinson's disease. Science 302:841. doi: 10.1126/science.1090278

Smith, W. W., Jiang, H., Pei, Z., Tanaka, Y., Morita, H., Sawa, A., et al. (2005). Endoplasmic reticulum stress and mitochondrial cell death pathways mediate A53T mutant alpha-synuclein-induced toxicity. Hum. Mol. Genet. 14, 38013811. doi: $10.1093 / \mathrm{hmg} / \mathrm{ddi} 396$

Snyder, H., Mensah, K., Theisler, C., Lee, J., Matouschek, A., and Wolozin, B. (2003). Aggregated and monomeric alpha-synuclein bind to the S6 proteasomal protein and inhibit proteasomal function. J. Biol. Chem. 278, 11753-11759. doi: 10.1074/jbc.m208641200

Spencer, B., Potkar, R., Trejo, M., Rockenstein, E., Patrick, C., Gindi, R., et al. (2009). Beclin 1 gene transfer activates autophagy and ameliorates the neurodegenerative pathology in alpha-synuclein models of Parkinson's and Lewy body diseases. J. Neurosci. Off. J. Soc. Neurosci. 29, 13578-13588. doi: 10.1523/jneurosci.4390-09.2009

Spillantini, M. G., Crowther, R. A., Jakes, R., Hasegawa, M., and Goedert, M. (1998). alpha-Synuclein in filamentous inclusions of Lewy bodies from Parkinson's disease and dementia with lewy bodies. Proc. Natl. Acad. Sci. U.S.A. 95, 64696473. doi: 10.1073/pnas.95.11.6469

Sriburi, R., Jackowski, S., Mori, K., and Brewer, J. W. (2004). XBP1: a link between the unfolded protein response, lipid biosynthesis, and biogenesis of the endoplasmic reticulum. J. Cell Biol. 167, 35-41. doi: 10.1083/jcb.20040 6136

Steet, R. A., Chung, S., Wustman, B., Powe, A., Do, H., and Kornfeld, S. A. (2006). The iminosugar isofagomine increases the activity of N370S mutant acid betaglucosidase in Gaucher fibroblasts by several mechanisms. Proc. Natl. Acad. Sci. U.S.A. 103, 13813-13818. doi: 10.1073/pnas.0605928103

Stefanis, L., Larsen, K. E., Rideout, H. J., Sulzer, D., and Greene, L. A. (2001). Expression of A53T mutant but not wild-type alpha-synuclein in PC12 cells induces alterations of the ubiquitin-dependent degradation system, loss of dopamine release, and autophagic cell death. J. Neurosci. Off. J. Soc. Neurosci. 21, 9549-9560. doi: 10.1523/jneurosci.21-24-09549.2001

Sun, Y., Liou, B., Xu, Y.-H., Quinn, B., Zhang, W., Hamler, R., et al. (2012). Ex vivo and in vivo effects of isofagomine on acid $\beta$-glucosidase variants and substrate levels in Gaucher disease. J. Biol. Chem. 287, 4275-4287. doi: 10.1074/jbc.M111. 280016

Suresh, S. N., Chavalmane, A. K., Dj, V., Yarreiphang, H., Rai, S., Paul, A., et al. (2017). A novel autophagy modulator 6-Bio ameliorates SNCA/ $\alpha$-synuclein toxicity. Autophagy 13, 1221-1234. doi: 10.1080/15548627.2017.1302045

Sveinbjornsdottir, S. (2016). The clinical symptoms of Parkinson's disease. J. Neurochem. 139(Suppl. 1), 318-324.

Tanaka, Y., Engelender, S., Igarashi, S., Rao, R. K., Wanner, T., Tanzi, R. E., et al. (2001). Inducible expression of mutant alpha-synuclein decreases proteasome activity and increases sensitivity to mitochondria-dependent apoptosis. Hum. Mol. Genet. 10, 919-926. doi: 10.1093/hmg/10.9.919

Tang, F.-L., Erion, J. R., Tian, Y., Liu, W., Yin, D.-M., Ye, J., et al. (2015). VPS35 in dopamine neurons is required for endosome-to-golgi retrieval of Lamp2a, a receptor of chaperone-mediated autophagy that is critical for $\alpha$-Synuclein degradation and prevention of pathogenesis of Parkinson's disease. J. Neurosci. Off. J. Soc. Neurosci. 35, 10613-10628. doi: 10.1523/jneurosci.0042-15.2015

Tanji, K., Miki, Y., Maruyama, A., Mimura, J., Matsumiya, T., Mori, F., et al. (2015). Trehalose intake induces chaperone molecules along with autophagy in a mouse model of Lewy body disease. Biochem. Biophys. Res. Commun. 465, 746-752. doi: 10.1016/j.bbrc.2015.08.076

Tenreiro, S., Reimão-Pinto, M. M., Antas, P., Rino, J., Wawrzycka, D., Macedo, D., et al. (2014). Phosphorylation modulates clearance of alpha-synuclein inclusions in a yeast model of Parkinson's disease. PLoS Genet. 10:e1004302. doi: 10.1371/journal.pgen.1004302

Tong, Y., Yamaguchi, H., Giaime, E., Boyle, S., Kopan, R., Kelleher, R. J., et al. (2010). Loss of leucine-rich repeat kinase 2 causes impairment of protein degradation pathways, accumulation of alpha-synuclein, and apoptotic cell death in aged mice. Proc. Natl. Acad. Sci. U.S.A. 107, 9879-9884. doi: 10.1073/ pnas. 1004676107

Ullrich, C., Mlekusch, R., Kuschnig, A., Marksteiner, J., and Humpel, C. (2010). Ubiquitin enzymes, ubiquitin and proteasome activity in blood mononuclear cells of MCI, Alzheimer and Parkinson patients. Curr. Alzheimer Res. 7, 549-555. doi: 10.2174/156720510792231766
Urra, H., Dufey, E., Lisbona, F., Rojas-Rivera, D., and Hetz, C. (2013). When ER stress reaches a dead end. Biochim. Biophys. Acta 1833, 3507-3517. doi: 10.1016/j.bbamcr.2013.07.024

Valdés, P., Mercado, G., Vidal, R. L., Molina, C., Parsons, G., Court, F. A., et al. (2014). Control of dopaminergic neuron survival by the unfolded protein response transcription factor XBP1. Proc. Natl. Acad. Sci. U.S.A. 111, 68046809. doi: 10.1073/pnas.1321845111

van Rooijen, B. D., Claessens, M. M. A. E., and Subramaniam, V. (2010). Membrane permeabilization by oligomeric $\alpha$-synuclein: in search of the mechanism. PLoS One 5:e14292. doi: 10.1371/journal.pone.0014292

Villar-Piqué, A., Lopes, da Fonseca, T., and Outeiro, T. F. (2016). Structure, function and toxicity of alpha-synuclein: the Bermuda triangle in synucleinopathies. J. Neurochem. 139(Suppl. 1), 240-255. doi: 10.1111/jnc. 13249

Vogiatzi, T., Xilouri, M., Vekrellis, K., and Stefanis, L. (2008). Wild type alphasynuclein is degraded by chaperone-mediated autophagy and macroautophagy in neuronal cells. J. Biol. Chem. 283, 23542-23556. doi: 10.1074/jbc.m80199 2200

Volpicelli-Daley, L. A., Gamble, K. L., Schultheiss, C. E., Riddle, D. M., West, A. B., and Lee, V. M.-Y. (2014). Formation of $\alpha$-synuclein Lewy neurite-like aggregates in axons impedes the transport of distinct endosomes. Mol. Biol. Cell 25, 4010-4023. doi: 10.1091/mbc.e14-02-0741

Wang, K., Huang, J., Xie, W., Huang, L., Zhong, C., and Chen, Z. (2016). Beclin1 and HMGB1 ameliorate the $\alpha$-synuclein-mediated autophagy inhibition in PC12 cells. Diagn. Pathol. 11:15.

Wang, L., Das, U., Scott, D. A., Tang, Y., McLean, P. J., and Roy, S. (2014). $\alpha$-synuclein multimers cluster synaptic vesicles and attenuate recycling. Curr. Biol. 24, 2319-2326. doi: 10.1016/j.cub.2014.08.027

Wang, X.-F., Li, S., Chou, A. P., and Bronstein, J. M. (2006). Inhibitory effects of pesticides on proteasome activity: implication in Parkinson's disease. Neurobiol. Dis. 23, 198-205. doi: 10.1016/j.nbd.2006.02.012

Waudby, C. A., Camilloni, C., Fitzpatrick, A. W. P., Cabrita, L. D., Dobson, C. M., Vendruscolo, M., et al. (2013). In-cell NMR characterization of the secondary structure populations of a disordered conformation of $\alpha$-synuclein within $E$. coli cells. PLoS One 8:e72286. doi: 10.1371/journal.pone.0072286

Webb, J. L., Ravikumar, B., Atkins, J., Skepper, J. N., and Rubinsztein, D. C. (2003). Alpha-Synuclein is degraded by both autophagy and the proteasome. J. Biol. Chem. 278, 25009-25013. doi: 10.1074/jbc.m300227200

Winner, B., Jappelli, R., Maji, S. K., Desplats, P. A., Boyer, L., Aigner, S., et al. (2011). In vivo demonstration that alpha-synuclein oligomers are toxic. Proc. Natl. Acad. Sci. U.S.A. 108, 4194-4199.

Winslow, A. R., Chen, C.-W., Corrochano, S., Acevedo-Arozena, A., Gordon, D. E., Peden, A. A., et al. (2010). $\alpha$-Synuclein impairs macroautophagy: implications for Parkinson's disease. J. Cell Biol. 190, 1023-1037. doi: 10.1083/jcb.201003122

Witt, S. N. (2013). Molecular chaperones, $\alpha$-synuclein, and neurodegeneration. Mol. Neurobiol. 47, 552-560. doi: 10.1007/s12035-012-8325-2

Wong, Y. C., and Krainc, D. (2017). $\alpha$-synuclein toxicity in neurodegeneration: mechanism and therapeutic strategies. Nat. Med. 23, 1-13. doi: 10.1038/nm. 4269

Wu, F., Xu, H.-D., Guan, J.-J., Hou, Y.-S., Gu, J.-H., Zhen, X.-C., et al. (2015). Rotenone impairs autophagic flux and lysosomal functions in Parkinson's disease. Neuroscience 284, 900-911. doi: 10.1016/j.neuroscience.2014.11.004

Xilouri, M., Brekk, O. R., Kirik, D., and Stefanis, L. (2013). LAMP2A as a therapeutic target in Parkinson disease. Autophagy 9, 2166-2168. doi: 10.4161/ auto. 26451

Xilouri, M., Vogiatzi, T., Vekrellis, K., Park, D., and Stefanis, L. (2009). Abberant alpha-synuclein confers toxicity to neurons in part through inhibition of chaperone-mediated autophagy. PLoS One 4:e5515. doi: 10.1371/journal.pone. 0005515

Xiong, N., Jia, M., Chen, C., Xiong, J., Zhang, Z., Huang, J., et al. (2011). Potential autophagy enhancers attenuate rotenone-induced toxicity in $\mathrm{SH}$ SY5Y. Neuroscience 199, 293-302.

Xu, C., Bailly-Maitre, B., and Reed, J. C. (2005). Endoplasmic reticulum stress: cell life and death decisions. J. Clin. Invest. 115, 2656-2664. doi: 10.1172/jci26373

Xu, S., Zhou, M., Yu, S., Cai, Y., Zhang, A., Uéda, K., et al. (2006). Oxidative stress induces nuclear translocation of C-terminus of alpha-synuclein in dopaminergic cells. Biochem. Biophys. Res. Commun. 342, 330-335. doi: 10. 1016/j.bbrc.2006.01.148 
Yang, C., Rahimpour, S., Lu, J., Pacak, K., Ikejiri, B., Brady, R. O., et al. (2013). Histone deacetylase inhibitors increase glucocerebrosidase activity in Gaucher disease by modulation of molecular chaperones. Proc. Natl. Acad. Sci. U.S.A. 110, 966-971. doi: 10.1073/pnas.1221046110

Yoshimoto, Y., Nakaso, K., and Nakashima, K. (2005). L-dopa and dopamine enhance the formation of aggregates under proteasome inhibition in PC12 cells. FEBS Lett. 579, 1197-1202. doi: 10.1016/j.febslet.2004.12.091

Yu, W. H., Dorado, B., Figueroa, H. Y., Wang, L., Planel, E., Cookson, M. R., et al. (2009). Metabolic activity determines efficacy of macroautophagic clearance of pathological oligomeric alpha-synuclein. Am. J. Pathol. 175, 736-747. doi: 10.2353/ajpath.2009.080928

Zimprich, A., Benet-Pagès, A., Struhal, W., Graf, E., Eck, S. H., Offman, M. N., et al. (2011). A mutation in VPS35, encoding a subunit of the retromer complex, causes late-onset Parkinson disease. Am. J. Hum. Genet. 89, 168-175. doi: 10.1016/j.ajhg.2011.06.008

Zimprich, A., Biskup, S., Leitner, P., Lichtner, P., Farrer, M., Lincoln, S., et al. (2004). Mutations in LRRK2 cause autosomal-dominant parkinsonism with pleomorphic pathology. Neuron 44, 601-607. doi: 10.1016/j.neuron.2004. 11.005

Zondler, L., Kostka, M., Garidel, P., Heinzelmann, U., Hengerer, B., Mayer, B., et al. (2017). Proteasome impairment by $\alpha$-synuclein. PLoS One 12:e184040. doi: 10.1371/journal.pone.0184040

Conflict of Interest Statement: The authors declare that the research was conducted in the absence of any commercial or financial relationships that could be construed as a potential conflict of interest.

Copyright (c) 2019 Lehtonen, Sonninen, Wojciechowski, Goldsteins and Koistinaho. This is an open-access article distributed under the terms of the Creative Commons Attribution License (CC BY). The use, distribution or reproduction in other forums is permitted, provided the original author(s) and the copyright owner(s) are credited and that the original publication in this journal is cited, in accordance with accepted academic practice. No use, distribution or reproduction is permitted which does not comply with these terms. 